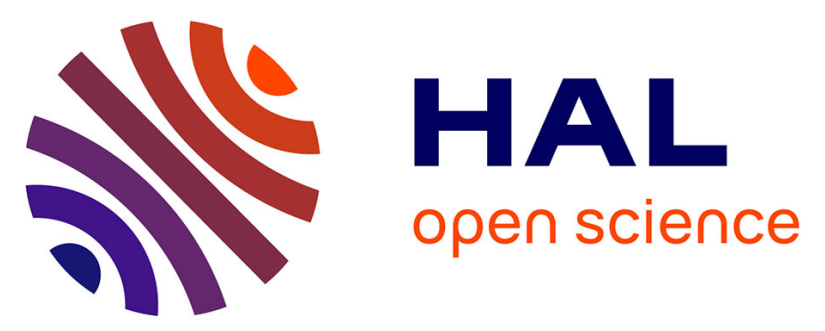

\title{
Ecological strategies of tree species in the laurel forest of Tenerife (Canary Islands): an insight into cloud forest natural dynamics using long-term monitoring data
}

Elias Ganivet, Olivier Flores, Eduardo Balguerias, Lea de Nascimento, José Ramón Arévalo, Silvia Fernández-Lugo, José María Fernández-Palacios

\section{To cite this version:}

Elias Ganivet, Olivier Flores, Eduardo Balguerias, Lea de Nascimento, José Ramón Arévalo, et al.. Ecological strategies of tree species in the laurel forest of Tenerife (Canary Islands): an insight into cloud forest natural dynamics using long-term monitoring data. European Journal of Forest Research, 2019, 138 (1), pp.93-110. 10.1007/s10342-018-1156-6 . hal-02877828

\section{HAL Id: hal-02877828 \\ https://hal.science/hal-02877828}

Submitted on 22 Jun 2020

HAL is a multi-disciplinary open access archive for the deposit and dissemination of scientific research documents, whether they are published or not. The documents may come from teaching and research institutions in France or abroad, or from public or private research centers.
L'archive ouverte pluridisciplinaire HAL, est destinée au dépôt et à la diffusion de documents scientifiques de niveau recherche, publiés ou non, émanant des établissements d'enseignement et de recherche français ou étrangers, des laboratoires publics ou privés. 


\title{
Ecological strategies of tree species in the laurel forest of Tenerife (Canary Islands): an insight into cloud forest natural dynamics using long-term monitoring data
}

Elias Ganivet ${ }^{1 *}$, Olivier Flores ${ }^{2}$, Eduardo Balguerías ${ }^{1}$, Lea de Nascimento $^{1}$, José Ramón Arévalo $^{1}$, Silvia Fernández-Lugo ${ }^{1}$ and José Maria Fernández-Palacios ${ }^{1}$

${ }^{1}$ Departamento de Botánica, Ecología y Fisiología Vegetal, Facultad de Ciencias, Universidad de La Laguna, La Laguna, Tenerife, Canary Islands, Spain.

${ }^{2}$ UMR Peuplements Végétaux et Bioagresseurs en Milieu Tropical, Université de la Réunion, Réunion Island, France.

"Corresponding author: ganivet.elias@gmail.com (orcid.org/0000-0002-8617-4188)

\begin{abstract}
In Tenerife (Canary Islands), the laurel forest is considered one of the most biodiverse ecosystems of the archipelago. This study aims at providing useful information about tree species strategies and their natural dynamics in order to improve understanding of the functioning of this ecosystem. The knowledge gained would be of great importance for laurel forest conservation, not only in the Canaries, but also in Madeira and the Azores. Our main research question is: 'Are the ecological groups of laurel forest tree species, described in earlier studies based exclusively on regeneration strategies, consistent with species functional traits, growth patterns and spatial distributions?' We used data from six $50 \times 50 \mathrm{~m}$ permanent plots established in 1999 and remeasured in 2015, combined with information on twelve functional traits from newly produced data or extracted from previous studies. For each species we analyzed the abundance of seedlings/suckers, saplings and adults inside the permanent plots. Two ordination methods were used to assess multivariate differences in functional traits between species. Different mixed-effect models were tested to investigate effects of sites, individual tree size and competition on tree growth rates. Finally we analyzed the spatial distribution of both saplings and adults and their interaction within the six permanent plots. Our results were consistent with a classification of species into different ecological groups based on (1) their shade-tolerance: light-demanding vs. shade-tolerant species and (2) their reproductive strategies: sexual (i.e. seedlings), asexual (i.e. suckers) or both. These differences between light-demanding vs. shade-tolerant and/or seedling-producing species vs. sucker-producing species were consistently observed across the species functional traits, growth patterns and spatial distributions. Only one species, Viburnum rigidum Vent., presented singularities compared with its previously established group. Because $V$. rigidum is mostly an understory species, we proposed to add a third aspect to the classification
\end{abstract}


scheme: understory vs. canopy species. This led to a total of six ecological groups within fourteen laurel forest tree species. Finally, this study also showed that the Tenerife laurel forest is still maturing and becoming richer in species, which outlines the importance of its preservation.

Keywords : Anaga Rural Park, Functional traits, Growth modeling, Laurel forests, Permanent plots, Spatial analyses, Tenerife.

\section{Introduction}

The laurel forest of the Canary Islands is considered the most emblematic ecosystem of the archipelago (Santos 1990; Fernández-Palacios et al. 2017). It forms a class of evergreen forests found in the Macaronesian biogeographical region (i.e. Azores, Madeira and Canary Islands) with, in the Canary Islands, a floristic composition encompassing up to nineteen broadleaf trees species mostly represented by the Lauraceae family (Apollonias barbujana (Cav.) Bornm., Laurus novocanariensis Rivas-Mart., Lousa, Fern. Prieto, E. Días, J.C. Costa \& C. Aguiar, Ocotea foetens (Aiton) Baill. and Persea indica C. K. Spreng.) (Santos 1990). In the Canary Islands, the laurel forest has been extensively exploited since the arrival of the early Castilian settlers in the fifteenth century (Parsons 1981). Nowadays, only 11.8 percent $(10,181$ ha) of the original laurel forest remains (del Arco et al. 2010), of which 85 percent is included in the Canarian Network of Protected Areas and up to 92 percent within the Natura 2000 European Union Network (Guimarāes and Olmeda 2008). There is therefore a need for basic ecological knowledge of this ecosystem in order to monitor the impact of conservation measures.

The importance of this ecosystem and the concern about its conservation has already led to an extensive literature on its ecology, with particular emphasis on natural forest regeneration (Arévalo and FernándezPalacios 1998, 2000, 2003, 2007; Fernández-Palacios and Arévalo 1998; Arévalo et al. 1999, 2007, 2008, 2011, 2012, 2018; Fernández-Palacios et al. 2004; Fernández-Lugo et al. 2014). These studies have defined a total of five ecological groups amongst the fourteen most abundant tree species (the rest of the species being very rare). Erica arborea L. and Erica scoparia L. were defined as 'pioneer species', being shade-intolerant and relying on an abundant seed bank for regeneration. A closely related type has been defined for Morella faya (Aiton) Wilbur as a long-lived pioneer species (also called 'persistent pioneer' in earlier studies), able to persist under a closed canopy due to its ability to also regenerate from suckers. Shade-tolerant species were divided into three groups, among which the 'itinerant species' (Heberdenia excelsa (Aiton) Banks ex DC., Picconia excelsa (Aiton) DC., Rhamnus glandulosa Aiton and Viburnum rigidum Vent.), relying entirely on the seedling bank, and the 'persistent species' (Ilex canariensis Poir., Ilex perado Aiton and Prunus lusitanica L.), relying mostly on asexual 
reproduction (i.e. suckers). The last group encompasses the Lauraceae family (i.e. A. barbujana, L. novocanariensis, $O$. foetens and $P$. indica) which have been classified as 'facultative species', relying on both seedlings and suckers to regenerate (Fernández-Palacios and Arévalo 1998; Fernández-Palacios et al. 2004; Fernández-Palacios 2009). Although included in earlier studies, to date no clear ecological strategy has been identified for the species Visnea mocanera L.f.. Our study aimed to improve the description of these ecological groups using new data while also focusing on three aspects other than regeneration.

Over the last decades, the description of ecological strategies, i.e. the ways species maintain persistent populations, has largely gained from functional ecology and the use of functional traits as proxies for strategies. Recent studies have suggested the existence of at least four trait-defined axes of plant strategies related to the stem-leaf-seed-size strategy scheme (Baraloto et al. 2010). Several traits from this scheme have been proposed to be universally important for plant performance and to represent important strategy axes (Westoby 1998; Westoby et al. 2002; Díaz et al. 2016). Wood density has been proposed as a core functional trait of the stem for woody species. It has been related to stem construction costs, plant architecture and stability and stem hydraulic conductance (King et al. 2006b; Chave et al. 2009; Anten and Schieving 2010; Markesteijn et al. 2011) and hence photosynthetic carbon gain (Santiago et al. 2004a). Leaf area indicates the efficiency for light capture (Poorter et al. 2009) while seed size is an important indicator of the life-history strategy of species, with fastgrowing pioneer species tending to have smaller seeds (Moles et al. 2004). Finally, maximum size, and especially height, determines the position of adult plants in the vertical profile of the vegetation, and hence their access to light (Hirose and Werger 1987).

However, functional traits cannot capture all aspects of ecological strategies, such as variation in growth along ontogeny for instance (Clark and Clark 1999; Poorter et al. 2005; Herault et al. 2011). Although description of growth strategies among tree species remains an important objective for forest management and conservation, to our knowledge, no study has modeled the individual tree growth of laurel forest tree species. In this study, using data from permanent plots we developed predictive models of diameter growth that improved the description of species growth strategies and their classification in ecological groups. Both variation along ontogeny and competition (Coomes 2006; Reich et al. 2006; Muller-Landau et al. 2006) were accounted for in our modeling approach. We expect early stages of ecological succession to be dominated by fast-growing species, known to be better colonists, and later successional stages to be dominated by slower growing species (Uhl and Jordan 1984; Lugo and Scatena 1996). 
Another critical aspect of plant strategies lies in their spatial patterns that are complex outcomes of the multiple ecological processes through which species interact with their environment. The spatial arrangement of tree communities is commonly studied to evaluate the combination of biotic and abiotic processes that act on individual survival and subsequently explains the presence/absence but also the abundance of species (Getzin et al. 2008). Studying the spatial distributions of trees is therefore important in ecological studies assuming that the currently-observed pattern should reflect the ecological processes resulting from the competition for resources, the suitability of habitats, niche differentiation and disturbances (Denslow 1987; Hubbell et al. 1999). Pioneer species are expected to be spatially aggregated, especially among seedlings and saplings, due to their positive association in younger stands with the high light availability within gaps created by tree-falls (Brokaw 1985a; Denslow 1987; Swaine and Whitmore 1988; Whitmore 1989). For all the others, the distribution of trees depends both on species biological traits (e.g. regeneration strategy) at a small-scale and on environmental heterogeneity at larger scales. In the laurel forest, spatial patterns of trees have been already described for some species (Arévalo and Fernández-Palacios 2003; Arévalo et al. 2012). Here we improved the knowledge of spatial patterns in the laurel forest using new data from large plots that also include species not studied earlier.

The general aim of this paper is to test the hypothesis that the ecological groups described in earlier studies, based exclusively on regeneration strategies, are consistent with species functional strategies (i.e. combination of functional traits), growth strategies (i.e. differences in growth patterns) and spatial patterns. Although studying regeneration might be less labor-intensive, the main purpose of bringing a new description of species ecological strategies using other aspects is to allow confirmation of the existing groups. This new information about species strategies will provide better understanding of the functioning of the laurel forests' natural dynamics that could be fundamental for planning restoration ecology projects or designing conservation policies. To achieve this goal, we first update information related to the regeneration strategies based on recently-surveyed permanent plots and assess functional strategies, growth strategies and spatial pattern separately. We then discuss all aspects together to clearly identify consistency amongst groups within either light-demanding or shade-tolerant species. The proposed classification will then be discussed to allow better understanding of the natural dynamics of the forest recorded using long-term monitoring data. The understanding gained by this study would thus be of great importance for laurel forest restoration and conservation in the whole Macaronesian region, especially under new, paramount threats, such as global warming. 


\section{Methodology}

\subsection{Study site}

The study was conducted in the north-eastern part of Tenerife in the Canary Islands $\left(28^{\circ} 19^{\prime} \mathrm{N}, 16^{\circ} 34^{\prime} \mathrm{W}\right)$, an archipelago located off the coast of Morocco in the north-east Atlantic (Fig. 1). The study sites are located in the Anaga Rural Park, a protected area located on a 7-8 million-year-old basaltic massif (Ancochea et al. 1990) ranging from sea level to $1024 \mathrm{~m}$ in altitude and covering a total of 14,224 ha, which represents about seven percent of the island's total surface. The mean annual rainfall ranges from $900 \mathrm{~mm}$ to twice this amount if the fog drip is included (Kämmer 1974). The mean annual temperature is about $15^{\circ} \mathrm{C}$ with few daily and annual fluctuations and no frost events. The topography of Anaga Rural Park is dominated by valleys, cliffs and ravines. A central ridge crossing the park separates well-defined southern or northern slopes leading to contrasting climate conditions (Morales and Pérez 2000). Influenced by the trade winds, the climate is wetter on the windward northern slopes due to the formation of a 'sea of clouds' (del Arco et al. 2010). 


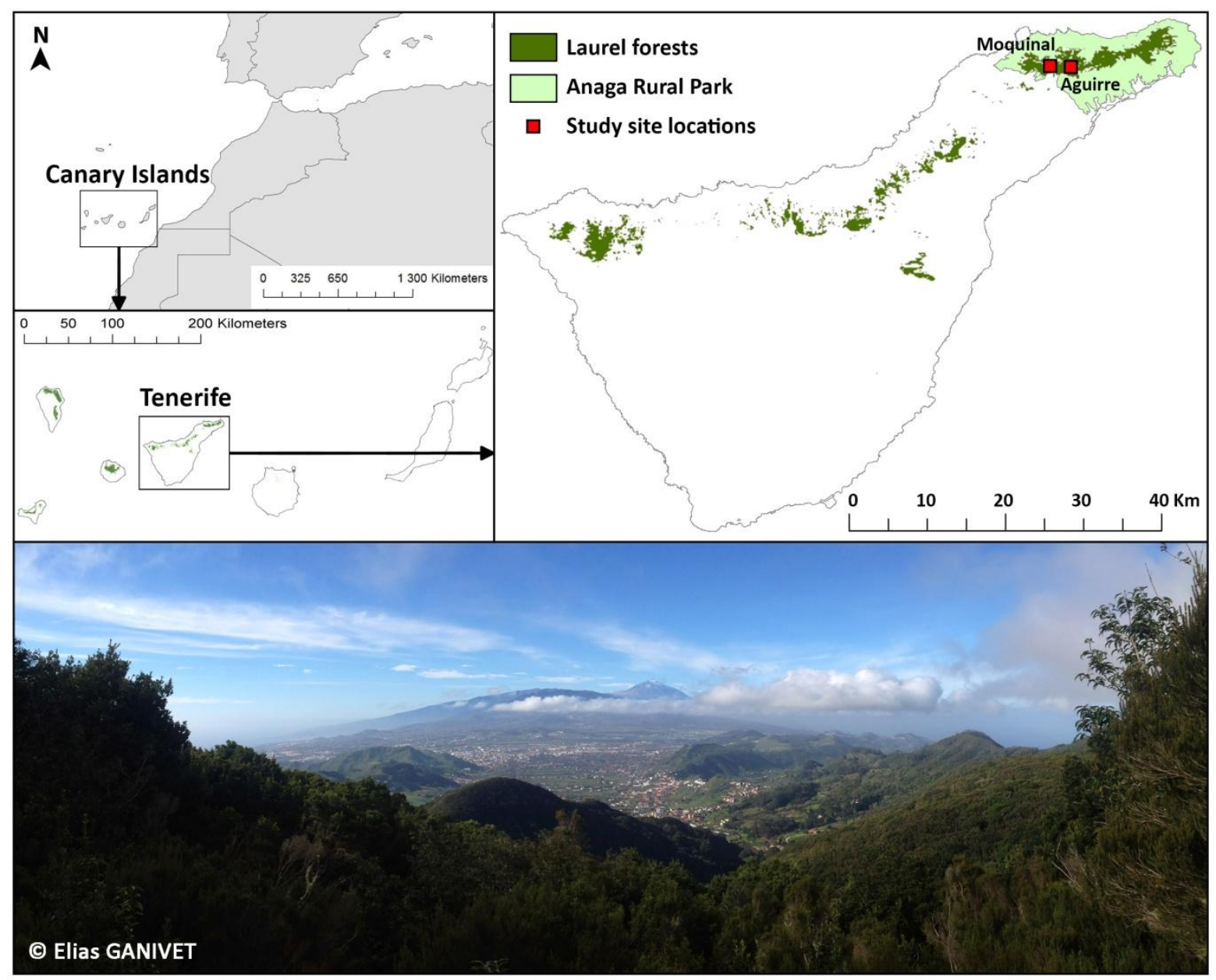

Figure 1: Location of the two sites where the study was conducted in the Anaga Rural Park of Tenerife, Canary Islands. Three 0.25 ha permanent plots were located in each site.

The Anaga Rural Park encompasses some of the best-preserved laurel forest remnants and is the most biodiverse part of the island. Laurel forest in Anaga harbors up to 19 evergreen broadleaf tree species (Santos 1990), with canopy height varying between 10 and $20 \mathrm{~m}$, depending on slope, and a canopy cover of 80-90\% in mature forests (Arévalo and Fernández-Palacios 2003; Arévalo et al. 2007). Although officially protected only since 1988, aerial photographs show that the forest has not experienced drastic changes since 1952 (Arévalo and Fernández-Palacios 2000). Nowadays, the laurel forest experiences almost no direct human-induced disturbances (i.e. grazing, agriculture, logging). 


\subsection{Data collection}

\subsubsection{Permanent plots}

We analyzed data from six 0.25 ha $(50 \times 50 \mathrm{~m})$ permanent plots randomly established in the Anaga Rural Park between June and September 1999 (see Appendix A for details). Three plots were established in Moquinal, on the windward side, and three others were established in Aguirre, on the leeward side (Fig. 1). Plots were 270-750 $\mathrm{m}$ apart in Aguirre, and 200-300 m apart in Moquinal. Each plot was subdivided into twenty-five $10 \times 10 \mathrm{~m}$ subplots permanently marked with iron bars. Inside these plots, all trees with a diameter at breast height (DBH) $\geq 3 \mathrm{~cm}$ were identified to species and measured in diameter. Dead trees $\geq 3 \mathrm{~cm}$ DBH were also measured in diameter if they were still standing. All smaller trees with a $\mathrm{DBH}<3 \mathrm{~cm}$ and a height $\geq 50 \mathrm{~cm}$ were identified to species, measured for height and recorded as either seedling (i.e. sexual reproduction) or sucker (i.e. asexual reproduction: sprouting at ground level from either a larger tree stem or a root). All plants were also mapped in the horizontal plane using measuring tapes. Finally, canopy, understory and rock cover were visually estimated (Appendix A).

Between March and September 2015, all plots were re-measured. The presence of iron bars in the ground made it possible to find the exact location of the six plots and all of their $10 \times 10 \mathrm{~m}$ subplots. Because the plots are located in a protected area, trees could not be permanently tagged in 1999. Although most of the trees could be found directly in the field from their coordinates, doing so was quite time-consuming. For that reason, all plots were eventually re-assessed in exactly the same way as it had been done in 1999. Living and dead trees $(\mathrm{DBH} \geq$ $3 \mathrm{~cm})$, seedlings and suckers $(\mathrm{DBH}<3 \mathrm{~cm})$ were measured either in DBH or height and mapped in the horizontal plane. Only live trees have been used for the analyses presented in the results.

\subsubsection{Functional traits}

Information on twelve key functional traits (related to the stem-leaf-seed-size strategy scheme) of laurel forest tree species was derived from newly produced data or extracted from previous studies (Appendix B). Details of sample collection and trait measurements are available in the study by Ohsawa and Nitta (1999) for the four leaf traits and in the study by Arévalo et al. (2007) for the six fruit and seed related traits. Although the maximum size usually refers to the maximum height, because we did not have this information we used the maximum $\mathrm{DBH}$ from the permanent plots instead. The 95th percentile diameters were used as estimates of maximum DBH to minimize the weight of outliers (e.g. King et al. 2006a; Hérault et al. 2011). 
In May 2015 we measured wood density of tree species by sampling wood cores from tree boles at DBH level using an increment borer (Haglöf, Västernorrland, Sweden). We sampled 10-15 wood cores of 15 species which represented a total of 170 trees. These trees were randomly sampled by walking in the forest in both the Moquinal and the Aguirre areas but outside the permanent plots. We measured wood density (in $\mathrm{g} / \mathrm{cm}^{3}$ ) following the standardized method suggested by Perez-Harguindeguy et al. (2013). First, we estimated the fresh volume $\left(\mathrm{V}\right.$ in $\left.\mathrm{cm}^{3}\right)$ of the wood samples using the dimensional method $\left[\mathrm{V}=(0.5 \times \mathrm{D})^{2} \mathrm{x} \pi \mathrm{x} \mathrm{L}\right]$. After removing the bark and trimming the extremities, we measured the length $(\mathrm{L}$ in $\mathrm{cm})$ of the wood cores using a caliper, the core diameter being fixed by the corer diameter $(D=0.515 \mathrm{~cm})$. Depending on the size of the sampled trees, the length of the wood cores ranged from 1.5 to $11.5 \mathrm{~cm}($ mean $=7.5 \mathrm{~cm})$. Finally, the wood cores were oven-dried at $70{ }^{\circ} \mathrm{C}$ for $72 \mathrm{~h}$ and weighed. Wood density was then computed as the ratio of the oven-dried mass of the wood core divided by its fresh volume.

\subsubsection{Growth data}

In order to obtain growth data from the permanent plots, we matched trees from 1999 and 2015 based on their coordinates, species and DBH: for each live tree with $\mathrm{DBH} \geq 3 \mathrm{~cm}$ inventoried in 2015 , we looked for conspecific live trees in 1999 with $\mathrm{DBH} \geq 3 \mathrm{~cm}$ and located at close coordinates in the same plot with a tolerance of $0.5 \mathrm{~m}$ distance. We only used matched data where only one pairing was possible and unambiguous. Some matches were removed to account for possible errors during measurements, recording, data entry or matching procedure. We assumed negative growth $<-0.2 \mathrm{~cm} / \mathrm{yr}$ and positive growth $>1.5 \mathrm{~cm} / \mathrm{yr}$ to be erroneous and we removed matches of trees exceeding these thresholds. The mean annual diameter increment (id in $\mathrm{cm} / \mathrm{yr}$ ) was then defined as the change in DBH between two measurements, divided by the number of years between measurements.

\subsection{Data analyses}

\subsubsection{Functional strategies}

All statistical analyses were performed using the R software v.3.2.2 (R Core Team 2015). We first followed a method proposed by Poorter et al. (2006) using a Canonical Discriminant Analysis (CDA) to analyze multivariate differences in functional traits between species. Because this analysis needed non-missing values, we removed Visnea mocanera and only used the four traits identified as key functional traits: wood density, leaf area, seed diameter and DBH95 (one for each component of the stem-leaf-seed-size scheme). We also tested if 
ordination could be improved using all twelve functional traits using the method proposed by Laliberté and Legendre (2010) to analyze the functional diversity of traits with missing values, which allowed the inclusion of Visnea mocanera. The complete set of functional traits was analyzed using the 'dbFD' function from 'FD' package (Laliberté et al. 2014). The multivariate association of species based on their functional traits was then analyzed using the Principal Coordinate Analysis (PCoA) produced by the 'dbFD' function.

\subsubsection{Growth strategies}

To account for the nested structure of our dataset (i.e. trees grouped within plots) we used a mixed-effect model approach and included the plot-specific effect as a random factor in our growth models. We used a mathematical model of ontogenetic growth trajectories described elsewhere as the tree size effect (King et al. 2006a; Herault et al. 2010). As a measure of tree size comparable across species, we used the ratio between the individual DBH and the 95th percentile of the species DBH distribution in the permanent plots (DBH95 in Appendix B). We included both the ratio and its squared value in the models to allow for a flexible mathematical form that can model either a monotonic increase, a monotonic decrease or a humped growth curve.

In order to quantify the effect of crowding, that can be expressed as negative (competition) or positive (facilitation) interactions between trees, we used a neighborhood crowding index (NCI) based on Lasky et al. (2015). This index integrates the relationship between the sizes of neighboring trees and their distance to the focal tree:

$$
N C I_{i}=\sum_{j=1}^{N} \frac{D B H_{j}}{D i s t_{i j}}
$$

with $D B H_{j}$ the diameter at breast height of the jth neighbor, and $D i s t_{i j}$ the distance between individual tree $i$ and its $j$ th neighbor within a maximum threshold distance $(d)$. The threshold distance (d) was varied successively from 2.5 to $20 \mathrm{~m}$ with a $2.5 \mathrm{~m}$ step increment in order to identify the best neighborhood in which interactions have significant effects. We used the method proposed by Goreaud and Pélissier (1999) for rectangular study areas to account for edge effects. The NCI index was standardized relative to the actual surface area of measurement (in $\mathrm{m}^{2}$ ), which depended on the varying distance (d) and the distance between the focal tree and the plot edges.

Considering the period between measurements (16 years), initial values of the index have less influence towards the end of this period. Instead, in order to account for possible changes in stand structure (and therefore 
crowding) over time, we used as explanatory variable the difference in NCI between 1999 and 2015 (i.e. $\Delta N C I=$ $\left.N C I_{2015}-N C I_{1999}\right)$. Finally, we log-transformed the response variable to control for heteroscedasticity and we added a constant (0.5) to account for retained negative values.

For each species the tested linear mixed model was constructed as :

$$
\begin{aligned}
& \log \left(i d_{i}+0.5\right)= \lambda_{1}+\lambda_{2} \times\left(\frac{D B H_{i}}{D B H 95}\right)+\lambda_{3} \times\left(\frac{D B H_{i}}{D B H 95}\right)^{2} \\
&+\lambda_{4} \times \Delta N C I_{(d) i}+\omega+\varepsilon \\
& \text { with } \omega \sim N\left(0, \sigma_{\omega}^{2}\right) \text { and } \varepsilon \sim N\left(0, \sigma_{\varepsilon}^{2}\right)
\end{aligned}
$$

with $i d_{i}$ the mean annual diameter increment of the individual tree $i$ of the focal species $; \lambda_{1}$ to $\lambda_{4}$ the fitted-model parameters fitted independently for each species ; $D B H_{i}$ the diameter at breast height of the individual tree $i$; DBH95 the 95th percentile of the DBH values of the focal species ; $\triangle N C I_{(d) i}$ the difference in the competition index calculated within a threshold distance (d) around the individual tree $i$ between 1999 and 2015; $\omega$ a plotspecific random effect and $\varepsilon$ the fitted-model residuals.

For each species we calibrated eight models, one for each threshold distances (d). We first controlled for collinearity in the explanatory variables using variance inflation factors (VIF, Zuur et al. 2009). Models were then fitted using the linear mixed-effect model function 'lmer' from the 'lme4' $\mathrm{R}$ package. The Akaike Information Criterion (AIC) was used in a stepwise procedure to choose the most parsimonious models and avoid over-parameterization (Legendre and Legendre 1998). Starting from a minimal model with only an intercept and a random plot effect, we sequentially added the remaining non-collinear variables and kept the model with the lowest AIC. This procedure produced a total of eight models per species of which we chose the one with the lowest AIC as the final model. Details about model selection are shown in Appendix C. Finally, two types of $\mathrm{R}^{2}$ (marginal and conditional $\mathrm{R}^{2}$ ) were calculated to disentangle the importance of the fixed and random effects (Nakagawa and Schielzeth 2013). Growth modeling was carried out only for species which had a minimum sample of 30 individuals with growth data.

\subsubsection{Spatial structure}

For all species, trees were classified as either saplings $(3 \leq \mathrm{DBH}<10 \mathrm{~cm})$ or adults $(\geq 10 \mathrm{~cm} \mathrm{DBH})$ in order to study the distribution of both stages and their interactions. The spatial patterns of both saplings and adults were described using $L(d)$, a transformation of the Ripley $K(d)$ function (Besag 1977; Ripley 1977): 


$$
L(d)=\sqrt{K(d) / \pi}-d
$$

The $L(d)$ function allows description of the spatial pattern of a species for distance (d), set here from 1 to $25 \mathrm{~m}$ with a $1 \mathrm{~m}$ step increment. The estimators of $L(d)$ were calculated using the local edge effect correction suggested by Ripley (1977) and extended by Goreaud and Pélissier (1999) to analyze areas of irregular shape. $L(d)=0$ under the null hypothesis of complete spatial randomness (CSR). For a given distance (d), $L(d)<0$ indicates that plants are regularly distributed and $L(d)>0$ indicates that plants are aggregated. The $99 \%$ confidence interval $\left(\mathrm{CI}_{99 \%}\right)$ of CSR was estimated using Monte Carlo simulations. A total of 1000 simulated realizations of a Poisson random process were used for each analysis (Ripley 1981).

We then analyzed the spatial interaction between adults and saplings using the linearized intertype $L_{12}(d)$ function (Lotwick and Silverman 1982; Goreaud and Pélissier 2003):

$$
L_{12}(d)=\sqrt{K_{12}(d) / \pi}-d
$$

$L_{12}(d)=0$ under the null hypothesis of independence between adult and sapling populations. For a given distance $d, L_{12}(d)<0$ indicates repulsion and $L_{12}(d)>0$ attraction between saplings and adults. For each analysis, a total of 1000 random toroidal shifts of adult trees relative to saplings were computed to build the $\mathrm{CI}_{99 \%}$ of population independence (Goreaud and Pélissier 2003). The minimum sample for spatial analyses was set at 30 individuals considering the data from 2015 only. The spatial analyses were carried out using the 'kfun' and ' $\mathrm{k} 12$ fun' functions from the 'ads' R package (Pélissier and Goreaud 2015).

\section{Results}

\subsection{Forest dynamics between 1999 and 2015}

A total of 2204 adults, 1588 saplings, 8258 suckers and 2968 seedlings belonging to 15 species were recorded, measured and mapped in the six plots in 2015 (Table 1). These numbers included only the live trees. The number of standing dead trees was 241 for adults and 665 for saplings (against 137 and 948 respectively in 1999). Overall the number of stems in the adult and sapling stands decreased between 1999 and 2015. At the same time, in each plot, species richness, basal area and quadratic mean diameter increased during this same interval. In 2015, as in 1999, plots in Aguirre were richer in species with fewer but larger trees than in Moquinal. 
Table 1: Stand characteristics for live trees of the six permanent plots in 1999 and 2015. QMD: Quadratic Mean Diameter.

\begin{tabular}{|c|c|c|c|c|c|c|c|c|c|c|c|c|}
\hline \multirow{2}{*}{ Variable } & \multicolumn{2}{|c|}{ Moquinal 1} & \multicolumn{2}{|c|}{ Moquinal 2} & \multicolumn{2}{|c|}{ Moquinal 3} & \multicolumn{2}{|c|}{ Aguirre 1} & \multicolumn{2}{|c|}{ Aguirre 2} & \multicolumn{2}{|c|}{ Aguirre 3} \\
\hline & 1999 & 2015 & 1999 & 2015 & 1999 & 2015 & 1999 & 2015 & 1999 & 2015 & 1999 & 2015 \\
\hline Adults $(\geq 10 \mathrm{~cm})$ & 326 & 382 & 386 & 364 & 391 & 496 & 410 & 331 & 381 & 352 & 356 & 279 \\
\hline Saplings $(<10 \mathrm{~cm})$ & 858 & 334 & 400 & 243 & 597 & 358 & 371 & 196 & 420 & 279 & 412 & 178 \\
\hline Suckers $(<3 \mathrm{~cm})$ & 827 & 1353 & 1212 & 1275 & 1690 & 2316 & 696 & 797 & 1022 & 1589 & 621 & 928 \\
\hline Seedlings $(<3 \mathrm{~cm})$ & 409 & 49 & 935 & 647 & 3546 & 574 & 504 & 1000 & 325 & 432 & 280 & 266 \\
\hline Species richness & 9 & 11 & 9 & 9 & 7 & 9 & 14 & 15 & 13 & 14 & 12 & 13 \\
\hline Basal area $\left(\mathrm{m}^{2} / \mathrm{ha}\right)$ & 37.6 & 44.4 & 38.5 & 44.7 & 33.3 & 40.0 & 46.9 & 52.1 & 46.9 & 51.3 & 39.2 & 42.0 \\
\hline QMD (cm) & 10.1 & 14.1 & 12.5 & 15.3 & 10.4 & 12.2 & 13.8 & 17.8 & 13.7 & 16.1 & 12.7 & 17.1 \\
\hline
\end{tabular}

Overall, most species did not experience drastic changes in relative density and basal area between 1999 and 2015 (Fig. 2). In both 1999 and 2015, the most abundant species were I. canariensis and L. novocanariensis in almost all plots. While dominating in abundance and basal area within the plots in Moquinal, P. lusitanica was almost absent in the plots from Aguirre area. Conversely, H. excelsa was quite abundant in the Aguirre area and absent in the Moquinal area. Due to their abundance, these species exhibited a high relative basal area in the plots. Some species such as M. faya and E. arborea also exhibited relatively high relative basal area but with low relative frequency. This indicates that these species were mostly represented by relatively large trees in the plots. In contrast, $V$. rigidum represented about $10 \%$ of the stems in some plots while it represented less than $1 \%$ of the relative basal area, which attests of the small size of the trees for that species. 


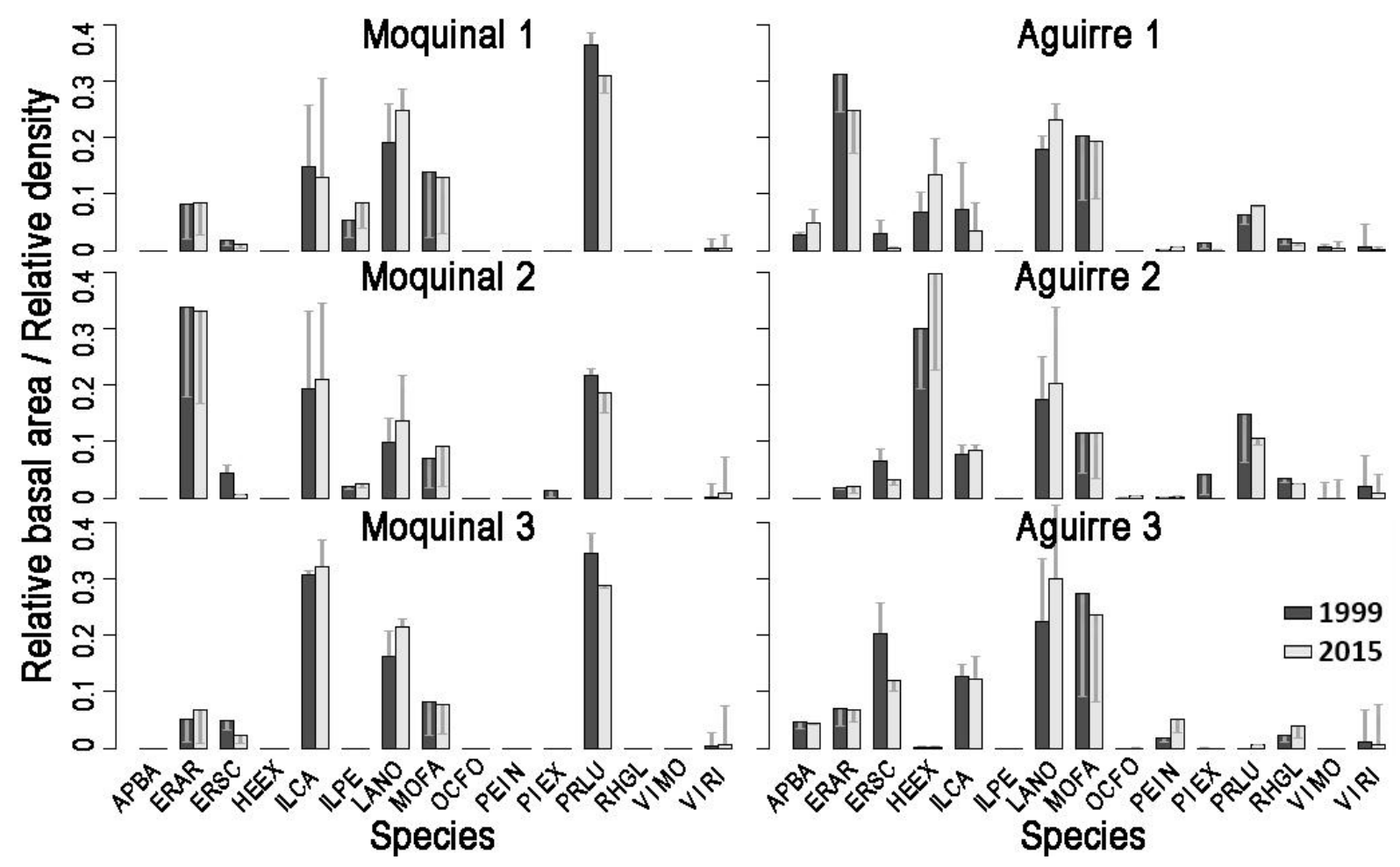

Figure 2: Relative basal area (dark and light grey bars) and relative stem density (vertical grey lines) of trees $\geq 3$ cm DBH (adults and saplings) of the 15 species from the six permanent plots in 1999 (dark grey) and 2015 (light grey). The vertical grey lines correspond to the difference between relative basal area and relative stem density. Thus the relative stem density must be read at the extremity of the lines. If the line is above the bar, the relative number of stems is higher than the relative basal area (i.e. small trees) while if the line is below the bar, the relative number of stems is lower than the relative basal area (i.e. large trees). Species names were abbreviated using the first two letters of the genus name followed by the first two letters of the species name. See abbreviation section for more details.

Only E. scoparia experienced relatively large changes in terms of stem density and basal area compared with the others. In some plots the species lost more than half of its relative number of stems and basal area. Even if overall the number of saplings decreased in all species between 1999 and 2015, with 207 adults and 189 saplings in the six plots in 1999, only 72 adults and 5 saplings of E. scoparia were present in 2015 (Table 2). E. arborea and M. faya also experienced a loss of adults and saplings, while adults increased in number in most of the other species, but these changes did not impact their relative basal area as much as was the case for E. scoparia. 
Table 2: Stand characteristics, plot distribution, number of matches of trees from 1999 and 2015 and associated mean annual diameter increment (id) of the 15 species from the six permanent plots. M: Moquinal. A: Aguirre. Adu.: adult trees. Sap.: saplings. QMD: Quadratic Mean Diameter. Species names were abbreviated using the first two letters of the genus name followed by the first two letters of the species name. See abbreviation section for more details.

\begin{tabular}{|c|c|c|c|c|c|c|c|c|c|c|c|c|c|c|}
\hline \multirow{2}{*}{ Species } & \multicolumn{2}{|c|}{ Adu. $(\geq 10 \mathrm{~cm})$} & \multicolumn{2}{|c|}{ Sap. $(<10 \mathrm{~cm})$} & \multicolumn{2}{|c|}{ Suckers } & \multicolumn{2}{|c|}{ Seedlings } & \multicolumn{2}{|c|}{ QMD (cm) } & \multicolumn{2}{|c|}{ Plots } & \multirow{2}{*}{ Match } & \multirow{2}{*}{$\begin{array}{c}\text { id } \\
(\mathrm{cm} / \mathrm{yr})\end{array}$} \\
\hline & 1999 & 2015 & 1999 & 2015 & 1999 & 2015 & 1999 & 2015 & 1999 & 2015 & 1999 & 2015 & & \\
\hline$\overline{\mathrm{APBA}}$ & 32 & 29 & 20 & 28 & 255 & 135 & 290 & 573 & 13.75 & 15.67 & $\mathrm{~A} 1 / 2 / 3$ & $\mathrm{M} 1-\mathrm{A} 1 / 2 / 3$ & 3 & 0.18 \\
\hline ERAR & 341 & 241 & 71 & 5 & 2 & 0 & 0 & 0 & 16.71 & 22.23 & All & All & 150 & 0.24 \\
\hline ERSC & 207 & 72 & 189 & 5 & 5 & 0 & 2 & 0 & 11.48 & 18.86 & All & All & 44 & 0.34 \\
\hline HEEX & 123 & 148 & 115 & 102 & 73 & 147 & 193 & 300 & 15.23 & 18.68 & $\mathrm{M} 1-\mathrm{A} 1 / 2 / 3$ & $\mathrm{M} 1-\mathrm{A} 1 / 2 / 3$ & 90 & 0.23 \\
\hline ILCA & 363 & 505 & 826 & 416 & 549 & 425 & 24 & 0 & 9.71 & 11.65 & All & All & 497 & 0.09 \\
\hline ILPE & 28 & 30 & 11 & 10 & 85 & 169 & 17 & 103 & 15.06 & 19.59 & M1-2 & $\mathrm{M} 1 / 2 / 3-\mathrm{A} 1$ & 18 & 0.26 \\
\hline LANO & 437 & 556 & 807 & 525 & 2224 & 2452 & 388 & 579 & 10.34 & 13.39 & All & All & 406 & 0.19 \\
\hline MOFA & 205 & 150 & 34 & 13 & 108 & 262 & 8 & 0 & 22.01 & 27.62 & All & All & 62 & 0.24 \\
\hline OCFO & 0 & 1 & 1 & 2 & 0 & 1 & 2 & 5 & 5.10 & 14.78 & A1/A2 & $\mathrm{A} 1 / 2 / 3$ & 1 & 0.11 \\
\hline PEIN & 9 & 18 & 1 & 0 & 2 & 32 & 1 & 11 & 16.42 & 21.66 & $\mathrm{~A} 1 / 2 / 3$ & $\mathrm{~A} 1 / 2 / 3$ & 2 & 0.21 \\
\hline PIEX & 9 & 0 & 2 & 1 & 2 & 0 & 14 & 73 & 29.46 & 4.80 & $\mathrm{M} 1-\mathrm{A} 1 / 2 / 3$ & All & 1 & 0.00 \\
\hline PRLU & 463 & 427 & 761 & 286 & 2206 & 3339 & 15 & 27 & 10.65 & 13.94 & All & All & 374 & 0.12 \\
\hline RHGL & 26 & 20 & 1 & 0 & 0 & 0 & 32 & 53 & 20.26 & 24.03 & $\mathrm{~A} 1 / 2 / 3$ & $\mathrm{~A} 1 / 2 / 3$ & 8 & 0.44 \\
\hline VIMO & 5 & 1 & 3 & 7 & 2 & 5 & 1 & 5 & 9.76 & 9.68 & A1 & $\mathrm{A} 1 / 2$ & 1 & 0.00 \\
\hline VIRI & 2 & 6 & 216 & 188 & 554 & 1291 & 5012 & 1239 & 5.55 & 5.06 & All & All & 51 & 0.03 \\
\hline
\end{tabular}

In terms of composition changes, the two Erica species, I. canariensis, L. novocanariensis, M. faya, P. lusitanica and $V$. rigidum were found in all plots both in 1999 and in 2015. Some species such as O. foetens, P. indica and R. glandulosa were found only in the Aguirre area in 1999 and 2015. And species such as A. barbujana and P. excelsa found only in the Aguirre area in 1999 were also found in the Moquinal area in 2015. Finally, all species found in Moquinal in 1999 were also found in 2015.

\subsection{Regeneration strategies}

From the data collected in 2015 and summarized in Table 2 we observed different patterns of regeneration amongst the laurel forest tree species. No regeneration was found for E. arborea and E. scoparia in all the plots (i.e. no suckers or seedlings). For M. faya and I. canariensis no seedlings were found but numerous suckers were recorded. Few seedlings were found for $P$. lusitanica compared with the large number of suckers. In contrast, no suckers but few seedlings were found for P. excelsa and $R$. glandulosa. For the remaining species we found both suckers and seedlings, although some species such as L. novocanariensis had more suckers than seedlings and $A$. barbujana and $H$. excelsa had more seedlings than suckers. 


\subsection{Functional strategies}

Both the principal coordinate analysis and the canonical discriminant analysis showed a significant separation of some functional groups based on their functional traits (Fig. 3). In the CDA, the first canonical discriminant function explained almost 97\% of the variation and separated the pioneers at the right, the long-lived pioneers, 'itinerant' and 'persistent' shade-tolerant species in the middle, and the 'facultative' shade-tolerant species at the left. The second canonical discriminant function only explained about $2 \%$ of the variation and did not really separate the species into distinctive groups. In the PCoA the first axis explained $48 \%$ of the variation and separated the 'facultative' shade-tolerant at the right, and the others in the middle. The second axis explained $15 \%$ of the variation and did not really separate the species into distinctive groups. Since adding more functional trait information did not improve the ordination, hereafter only results from the CDA will be used.
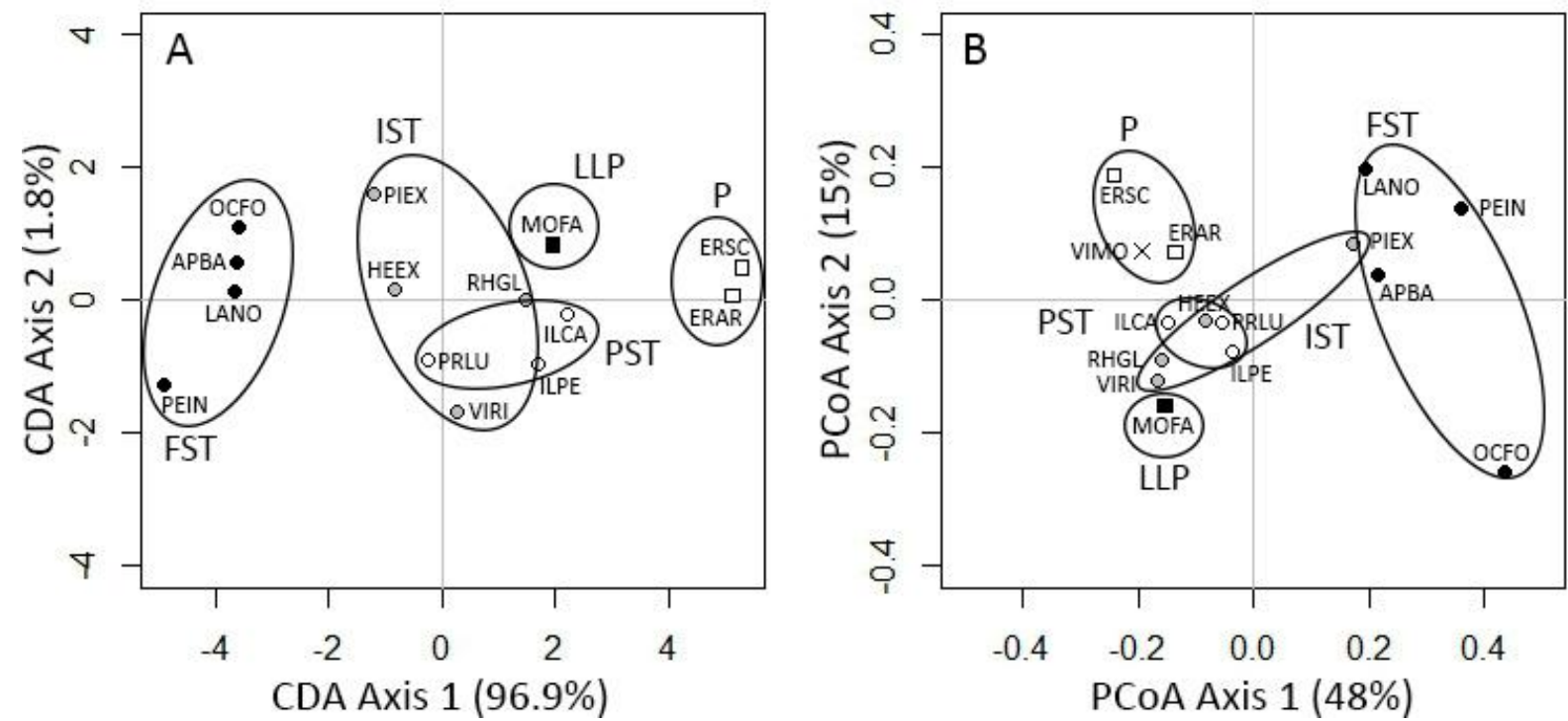

Figure 3: Canonical discriminant analysis (A) and Principal coordinate analysis (B) of functional traits of 14 (A) and 15 (B) laurel forest tree species. The scores along the first two axes are shown. Based on earlier studies species were grouped into different shade-tolerance guilds indicated with different symbols. Pioneer $(\mathrm{P})$ : white square; Long-lived pioneer (LLP): black square; 'Itinerant' shade-tolerant (IST): grey circle; 'Persistent' shadetolerant (PST): open circle; 'Facultative' shade-tolerant (FST): black circle and Unknown: black cross (VIMO). Species group are indicated by ovals. Abbreviations refer to the first two letters of the genus name followed by the first two letters of the species name. See abbreviation section for more details.

The pioneers and the 'facultative' shade-tolerant were found clearly separated from the others. The two pioneers E. arborea and E. scoparia were characterized by heavy wood densities, small-sized leaves and seeds and medium maximum sizes. The long-lived pioneer $M$. faya was found at the boundary of the pioneers with the 
same characteristics, except a larger maximum size. At the opposite was found the 'facultative' shade-tolerant group composed by A. barbujana, L. novocanariensis, $O$. foetens and $P$. indica. This group mixed light $(P$. indica) to heavy (A. barbujana) wood densities with large-sized leaves and seeds and large maximum sizes. Finally, the separation was not obvious between the two remaining groups ('itinerant' and 'persistent' shadetolerant), although they were well separated from the pioneers and 'facultative' shade-tolerant. They were characterized by medium wood densities, medium-sized leaves and seeds and small to large maximum sizes. According to its functional traits, $V$. rigidum was closer to the 'persistent' than the 'itinerant' shade-tolerant group in which it has been classified in earlier studies.

\subsection{Growth strategies}

In total, 1708 trees $\geq 3 \mathrm{~cm}$ DBH from both 1999 and 2015 were matched allowing us to obtain growth data for all species. The average growth rate was $0.18 \mathrm{~cm} /$ year, with wide variation across species (Table 2). However, for the analysis we removed species with less than 30 individuals: growth modeling was eventually carried out using 1674 trees belonging to eight species only. For these species, growth rates also varied widely among individual trees of the same size (Fig. 4). The linear mixed-effect modeling approach explained between $35 \%$ and $64 \%$ of the variation in growth rates considering only the fixed effects, and between $35 \%$ and $66 \%$ with the random effect (Table 3). No effect of the plot was found for E. arborea, H. excelsa and V. rigidum (0\%). Although relatively stronger on $M$. faya (14\%), only a limited plot effect was found for most of the other species $(1-5 \%)$. The threshold distance (d) for calculation of $\Delta \mathrm{NCI}$ that best explained the tree growth rates was $2.5 \mathrm{~m}$ for almost all species. Only $H$. excelsa and L. novocanariensis had their growth rates best explained for distances of 20 and $5 \mathrm{~m}$ respectively. 

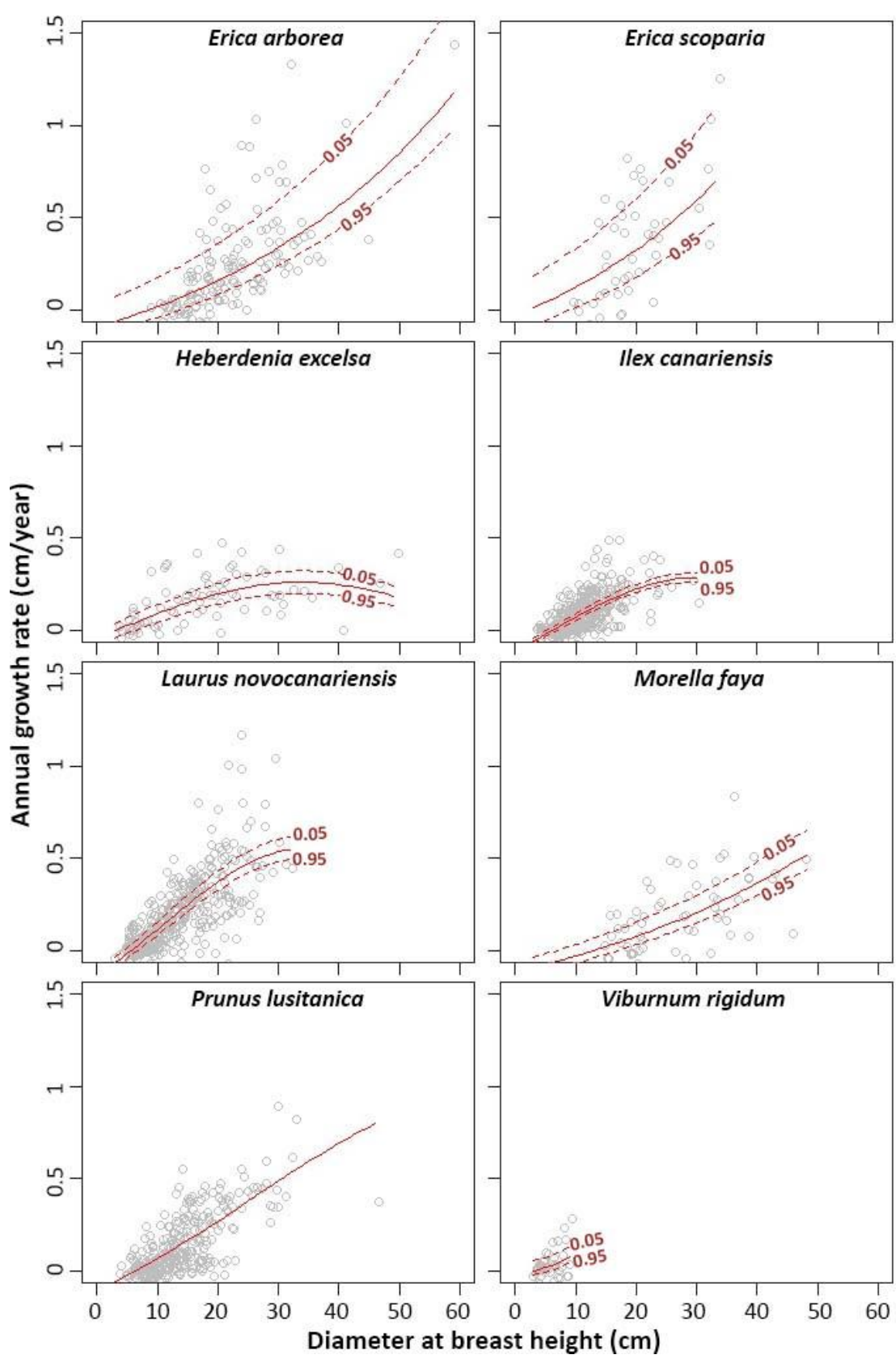

Figure 4: Modeled growth trajectories of eight laurel forest tree species. Observed annual growth rates plotted against the observed tree diameters at breast height (grey circles). The curves indicate the predictions of the linear mixed model. Continuous red lines are predicted growths for a mean value of $\triangle N C I$ while dotted red lines represent growth predictions for 5\% and $95 \%$ quantiles of $\triangle N C I$.

An effect of ontogeny on the growth rate ( $\lambda_{2}$ and/or $\lambda_{3}$ ) was found for the eight species (Table 3). The parameter for ontogeny was almost always the first selected in the model selection, whatever the species and the threshold distance (Appendix C). E. scoparia, E. arborea, M. faya and V. rigidum exhibited an exponential increase in growth with increasing size (positive $\lambda_{2}$ or positive $\lambda_{3}$ ) while the five others had model parameters for humped 
growth responses (positive $\lambda_{2}$ and negative $\lambda_{3}$; Fig. 4). However, only H. excelsa reached its maximum growth rate within our measured diameter range (at $35 \mathrm{~cm} \mathrm{DBH),} \mathrm{with} \mathrm{growth} \mathrm{rates} \mathrm{gently} \mathrm{decreasing} \mathrm{above} \mathrm{this}$ diameter. For I. canariensis, the maximum growth rate was reached at about $30 \mathrm{~cm}$, which was the extreme of the measured diameter range for this species. Even if L. novocanariensis exhibited a slightly curved growth, no maximum threshold was reached within the diameter range. Finally, P. lusitanica exhibited almost a linear increase of growth rate with increasing size within the complete measured diameter range.

Table 3: Effect of tree size and competition on the growth rates of 8 laurel forest tree species. Numbers in parenthesis are standard deviations. The Akaike information criterion was used to choose the most parsimonious model. $\mathrm{d}$ is the threshold distance selected by AIC for the calculation of the NCI index. $D: D B H / D B H 95 . D 2$ : $(\mathrm{DBH} / \mathrm{DBH} 95)^{2}$. Marginal $\mathrm{R}^{2}$ : fixed effects only. Conditional $\mathrm{R}^{2}$ : fixed and random effects. More details about model selection and model validation are shown in Appendix C. Species names were abbreviated using the first two letters of the genus name followed by the first two letters of the species name. See abbreviation section for more details.

\begin{tabular}{|c|c|c|c|c|c|c|c|c|c|}
\hline Species & d (m) & $\begin{array}{c}\text { Inter. } \\
\lambda_{1}\end{array}$ & $\begin{array}{l}D \\
\lambda_{2}\end{array}$ & $\begin{array}{c}D 2 \\
\lambda_{3}\end{array}$ & $\begin{array}{c}\Delta N C I_{(d)} \\
\lambda_{4}\end{array}$ & $\begin{array}{c}\text { Rand. } \\
\omega\end{array}$ & $\begin{array}{c}\text { Resid. } \\
\varepsilon\end{array}$ & $\begin{array}{c}\text { Marg } \\
. \mathbf{R}^{2}\end{array}$ & $\begin{array}{c}\text { Cond. } \\
\mathbf{R}^{2}\end{array}$ \\
\hline$\overline{\text { ERAR }}$ & 2.5 & $-0.96(0.05)$ & $0.72(0.07)$ & - & $-0.04(0.005)$ & $0(0)$ & $0.04(0.21)$ & 0.58 & 0.58 \\
\hline ERSC & 2.5 & $-0.94(0.13)$ & $0.55(0.13)$ & - & $-0.03(0.006)$ & $0.005(0.07)$ & $0.04(0.23)$ & 0.60 & 0.64 \\
\hline HEEX & 20 & $-0.85(0.05)$ & $0.99(0.18)$ & $-0.48(0.13)$ & $-1.19(0.37)$ & $0(0)$ & $0.02(0.15)$ & 0.48 & 0.48 \\
\hline ILCA & 2.5 & $-0.99(0.04)$ & $0.81(0.10)$ & $-0.23(0.06)$ & $-0.01(0.003)$ & $0.001(0.04)$ & $0.02(0.12)$ & 0.42 & 0.47 \\
\hline LANO & 5 & $-1.06(0.04)$ & $1.31(0.13)$ & $-0.40(0.09)$ & $-0.09(0.02)$ & $0.002(0.04)$ & $0.03(0.16)$ & 0.64 & 0.66 \\
\hline MOFA & 2.5 & $-0.96(0.11)$ & $0.82(0.13)$ & - & $-0.02(0.01)$ & $0.01(0.11)$ & $0.04(0.19)$ & 0.42 & 0.56 \\
\hline PRLU & - & $-0.98(0.04)$ & $0.81(0.10)$ & $-0.12(0.06)$ & - & $0.002(0.04)$ & $0.03(0.16)$ & 0.51 & 0.54 \\
\hline VIRI & 2.5 & $-0.73(0.25)$ & - & $0.15(0.05)$ & $-0.03(0.01)$ & $0(0)$ & $0.009(0.10)$ & 0.35 & 0.35 \\
\hline
\end{tabular}

A negative effect of $\triangle N C I\left(\lambda_{4}\right)$ on growth rates was found for all species except $P$. lusitanica. This result indicates that a decrease in competition between 1999 and 2015 led to higher growth rates. According to the model predictions (Fig. 4), the effect of $\triangle N C I$ was stronger on E. arborea, E. scoparia, H. excelsa and M. faya than on the other species (i.e. wider variations of growth predictions between $5 \%$ and $95 \%$ quantiles of $\triangle N C I$ values).

\subsection{Spatial structure}

Due to the minimum number of 30 individuals requested, spatial analyses were only performed on the same eight species as the growth modeling analysis. For the eight species, spatial distribution, spatial pattern analysis of both saplings and adults as well as their interaction are shown in Appendix D. These results have been summarized in Table 4. For some species the number of individuals did not allow to do the analysis in both 
stands. Spatial analysis was carried out only on the adult stands for E. arborea, E. scoparia and M. faya. Analysis revealed a strong aggregation, even at long distances, of the adults of $E$. scoparia in Aguirre 3 and $E$. arborea in Moquinal 2. Surprisingly, adults of E. arborea were found randomly distributed in Aguirre 1. On the other hand, adults of M. faya showed an aggregation at shorter distances: less than $5 \mathrm{~m}$ in Aguirre 1 and less than $10 \mathrm{~m}$ in Aguirre 3.

Table 4: Spatial patterns of saplings $(\mathrm{DBH}<10 \mathrm{~cm})$ and adults $(\mathrm{DBH} \geq 10 \mathrm{~cm})$ of 8 laurel forest species and their interaction in the study plots (data from 2015). Ag.: aggregated spatial pattern, Ra.: random spatial pattern. At.: attraction between point patterns. Numbers under parenthesis correspond to the distance. (-): analysis not performed due to the low number of individuals $(<30)$ in the adult or sapling stand. Species names were abbreviated using the first two letters of the genus name followed by the first two letters of the species name. See abbreviation section for more details.

\begin{tabular}{|c|c|c|c|c|}
\hline Species & Plot & Saplings & Adults & Interaction \\
\hline \multirow{2}{*}{ ERAR } & Moquinal 2 & - & Ag. (1-25m) & - \\
\hline & Aguirre 1 & - & Ra. $(1-25 m)$ & - \\
\hline ERSC & Aguirre 3 & - & Ag. $(1-25 m)$ & - \\
\hline \multirow{2}{*}{ HEEX } & Aguirre 1 & Ag. $(1-25 m)$ & Ag. $(1-25 m)$ & At. (8-12m) \\
\hline & Aguirre 2 & Ag. $(1-25 m)$ & Ag. $(3-25 m)$ & At. $(8-20 \mathrm{~m})$ \\
\hline \multirow{5}{*}{ ILCA } & Moquinal 1 & Ag. $(1-25 m)$ & Ag. (1-4m) & At. $(1-3 m)$ \\
\hline & Moquinal 2 & Ag. $(1-25 m)$ & Ag. $(1-25 m)$ & At. $(1-2 m)$ \\
\hline & Moquinal 3 & Ag. $(1-10 m)$ & Ag. $(1-4 m)$ & At. $(1-2 m)$ \\
\hline & Aguirre 2 & - & Ag. $(1-4 m)$ & - \\
\hline & Aguirre 3 & - & Ag. $(1-4 m)$ & - \\
\hline \multirow{6}{*}{ LANO } & Moquinal 1 & Ag. (1-3m) & Ag. (1-4m) & At. $(1-3 m)$ \\
\hline & Moquinal 2 & Ag. (1-4m) & Ag. $(1-3 m)$ & At. $(1-2 m)$ \\
\hline & Moquinal 3 & Ag. $(1-3 m)$ & Ag. $(1-2 m)$ & At. $(1-2 m)$ \\
\hline & Aguirre 1 & Ag. $(1-2 m)$ & Ag. $(1-2 m)$ & At. $(1-2 m)$ \\
\hline & Aguirre 2 & Ag. $(1-4 m)$ & Ag. $(1-3 m)$ & At. $(1-3 m)$ \\
\hline & Aguirre 3 & Ag. $(1-3 m)$ & Ag. $(1-3 m)$ & At. $(1-3 m)$ \\
\hline \multirow{2}{*}{ MOFA } & Aguirre 1 & - & Ag. $(1-5 m)$ & - \\
\hline & Aguirre 3 & - & Ag. $(1-8 m)$ & - \\
\hline \multirow{4}{*}{ PRLU } & Moquinal 1 & Ag. $(1-25 m)$ & Ag. (1-5m) & At. $(1-2 m)$ \\
\hline & Moquinal 2 & - & Ag. $(1-5 m)$ & - \\
\hline & Moquinal 3 & Ag. $(1-2 m)$ & Ag. $(1-3 m)$ & At. $(1-2 m)$ \\
\hline & Aguirre 2 & Ag. (1-5m) & Ag. $(1-18 m)$ & At. (1-3m) \\
\hline \multirow{3}{*}{ VIRI } & Moquinal 2 & Ag. (3-25m) & - & - \\
\hline & Moquinal 3 & Ag. $(3-10 \mathrm{~m})$ & - & - \\
\hline & Aguirre 3 & Ra. & - & - \\
\hline
\end{tabular}

Both adults and saplings of $H$. excelsa were found aggregated, even at long distances, in both Aguirre 1 and 2. Also in both plots, a really small but significant attraction between adults and saplings was found. For $V$. rigidum the analysis was carried out only on saplings. The results were quite different between the plots for this species: 
aggregated over long distances in Moquinal 2, over smaller distances $(<10 \mathrm{~m})$ in Moquinal 3 and randomly distributed in Aguirre 3. The last three species I. canariensis, L. novocanariens and P. lusitanica showed similar spatial patterns and interactions in both stands. In the six plots and in both stands, L. novocanariens was always found aggregated at very short distances $(<5 \mathrm{~m})$. Saplings and adults of $I$. canariensis and P. lusitanica were also found aggregated at short distances $(<5$ or $10 \mathrm{~m})$ in most of the plots and aggregated over longer distances in few plots. For all three species, a significant attraction at very short distances $(<3 \mathrm{~m})$ was found between the saplings and adults.

\section{Discussion}

\subsection{Light-demanding strategies}

In terms of ecological strategies our results are relatively consistent with what was proposed in earlier studies (Fernández-Palacios and Arévalo 1998; Fernández-Palacios et al. 2004; Fernández-Palacios 2009). While relatively abundant in the canopy as adult trees, no regeneration was found for E. arborea and E. scoparia in 2015. This further supports these species having a pioneer reproductive strategy (Whitmore 1989) and being unable to germinate under the shady conditions of a closed canopy (Arévalo and Fernández-Palacios 2000; Fernández-Palacios et al. 2004). On the other hand, numerous suckers were recorded for M. faya, attesting its ability to persist under a closed canopy, which supports results from earlier studies and its classification as a long-lived pioneer. Based on their functional traits, these three species were also well separated from the shadetolerant groups. Species could even be ranked along the first CDA axis according to their supposed shadetolerance. The most light-demanding species were grouped at the right while the most shade-tolerant species were grouped at the left. M. faya was found at the boundary between the two other pioneers and the first shadetolerant group, which further supports its classification as a long-lived pioneer.

The three species are characterized by small-sized seeds, which is a usual pattern for light-demanding pioneer species (Moles et al. 2004), allowing a better dispersion and enhancing the chance of reaching favorable habitats (Whitmore 1989). The small size of their leaves could also reflect their strategy as pioneers. Combined with a closely ramified branching, this trait seems better suited to strong light environments (Westoby et al. 2002) and explains why these species are unable to survive as seedlings in the shady conditions of the understory. On the other hand, their high wood density is not consistent with what is expected for fast-growing pioneer species (Chave et al. 2006), usually characterized by low-cost conductive tissues of low wood density (ter Steege and Hammond 2001; Wright et al. 2003; Muller-Landau 2004). We can hypothesize that these species have 
developed specific strategies, probably related to local climatic conditions. Indeed, high wood density usually provides a lower vulnerability to drought stress (Carlquist 1977; Tyree and Sperry 1989; Hacke et al. 2001; Meinzer 2003), as well as stronger defenses against predators, pathogens and physical damages (Rowe and Speck 2005).

However, while high wood density is supposed to be more expensive to construct, resulting in lower growth in size (Favrichon 1994; Suzuki 1999; Santiago et al. 2004b), these three species had amongst the highest growth rates recorded. This result is even more surprising for E. arborea and E. scoparia considering their low growth rates (decreasing at larger diameters) recorded in Madeira (Pupo-Correia 2016). Fernández-Palacios et al. (2017) hypothesized that these two pioneers have high growth rates when young, in order to reach the canopy, but have a slower growth afterwards, explaining this high wood density. However, this is not supported by our results: both species had their growth increasing as an exponential of size, with no decrease at larger diameters, even though we had a larger diameter range than Pupo-Correia (2016). On the other hand, Pupo-Correia (2016) used only dendrochronological data and, for these two species, growth rings were not clearly defined with annual regularity or reliable cyclic increment which might explain this difference. We can also identify some limitations of our method since growth data were obtained from trees that were not permanently tagged.

Thus, although higher growth rates support their strategy as pioneers needing to reach the canopy faster than other species (Uhl and Jordan 1984; Lugo and Scatena 1996), doing so while producing high wood density is a singular feature of these species within the laurel forest. A slightly slower growth trajectory was recorded for $M$. faya which is consistent for a long-lived pioneer species that does not need to grow as fast as classic pioneers (Lusk 1999). Interestingly, these three species presented more variation in growth in response to $\Delta \mathrm{NCI}$ compared with the others. This suggests their growth is probably more dependent on resource availability, which is consistent for light-demanding species (Whitmore 1989). M. faya exhibited a slightly slower growth response to changing crowding. We hypothesize that its ability to also produce suckers might mitigate the effect of competition by allowing root transfer of resources from the mother tree. We also hypothesize that the $2.5 \mathrm{~m}$ threshold distance (d) recorded for almost all species can be a consequence of the dense low canopy of the laurel forest, which increase short distance crowding effects.

Finally, based on their spatial distribution, no difference could be found between light-demanding and shadetolerant species: all presented a persistent aggregated spatial pattern. Nevertheless, differences in the scale of aggregation allowed to differentiate two major groups: species relying on seedlings for regeneration (seedling- 
producing species), aggregated at long distances, and species relying on suckers for regeneration (suckerproducing species), aggregated at shorter distances. This result is consistent with what was reported by Arévalo and Fernández-Palacios (2003) on a fewer number of species. Overall, E. arborea and E. scoparia formed aggregates on large distances (up to $25 \mathrm{~m}$ ) while $M$. faya was found aggregated at shorter distances (1-8 m), which is consistent with its ability to regenerate from seedlings and sometimes from suckers. The aggregations observed for these three species is a usual pattern for pioneers (Brokaw 1985b; Swaine and Whitmore 1988), due to their association with tree-fall gaps (Niiyama et al. 1999). The random distribution observed for E. arborea in Aguirre 1 can eventually be explained by the high mortality recorded in this plot, which could have resulted in a shift towards a random pattern (Gavin and Peart 1997).

\subsection{Shade-tolerant strategies}

Only based on regeneration, our results are consistent with earlier studies and also suggest the existence of three ecological groups in the shade-tolerant species: seedling-producing species, sucker-producing species or both seedling- and sucker-producing species (Fernández-Palacios and Arévalo 1998; Fernández-Palacios et al. 2004; Fernández-Palacios 2009). The first group, classified as 'itinerant species' in earlier studies, encompassed $P$. excelsa and $R$. glandulosa and relied entirely on the seedling bank for regeneration (no suckers recorded). Although $H$. excelsa and V. rigidum were found with both seedlings and suckers, based on field observations we believe these species also rely almost entirely on seedlings for regeneration. For both species, most suckers identified in 2015 were branches sprouting from the base of seedlings/saplings and were more likely related to development than asexual reproduction. The second group, classified as 'persistent species', encompassed $I$. canariensis, I. perado and P. lusitanica and relied almost entirely on asexual reproduction. The last group, classified as 'facultative species', encompassed A. barbujana, L. novocanariensis, O. foetens and P. indica and relied on both seedlings and suckers. Part of this classification is not only based on the data from the permanent plots but also from personal field observations, especially for some species such as $O$. foetens where too few data were recorded in the plots.

In terms of functional strategies, the differences among the shade-tolerant species were not as clear as between shade-tolerant vs. light-demanding species. Only the 'facultative' species were well separated from the other groups at the left of the first CDA axis. A key characteristic of this group was the large size of their seeds, suggesting low dispersal abilities (Seidler and Plotkin 2006) which is a usual pattern for shade-tolerant species. Although 'itinerant' and 'persistent' groups were ranked in-between the 'facultative' shade-tolerant and the light- 
demanding species, no clear boundaries were found between them due to the outlier V. rigidum. Based on its functional traits, this species could be either a 'persistent' shade-tolerant or form a new group. Since its regeneration does not only rely on asexual reproduction like the 'persistent species', it is unlikely that $V$. rigidum has the same strategy. We suggest this species has its own strategy which was not reported in earlier studies. Formerly described as a tree, Fernández-Palacios et al. (2017) more recently described that species rather as a tall shrub able to grow to a small tree. While the other species are found in the understory as seedlings/saplings and reach canopy status with increasing ontogeny, $V$. rigidum usually remains as a small tree $($ DBH95 $=8.9 \mathrm{~cm})$ in the understory. However, contrary to Fernández-Palacios et al. (2017), we prefer describing that species as an understory tree rather than a tall shrub as it presents characteristics more consistent with a tree than a shrub habit (e.g. stem architecture, leaf size). Its large leaves are therefore probably an adaptation to enhance light capture under the shady conditions of the understory.

In terms of growth strategies, our results remain consistent with regeneration and functional strategies outlined by stage-specific abundance and functional traits. H. excelsa was the only species exhibiting decreasing growth after its maximum growth rate was reached at about $35 \mathrm{~cm}$ DBH. Modeling the growth of another 'itinerant species' would have been useful to see if this growth pattern is typical of seedling-producing shade-tolerant species. I. canariensis, L. novocanariensis and $P$. lusitanica also had model parameters allowing for a humped growth trajectory. However, in our measured diameter ranges, maximum growth rates were reached only by $I$. canariensis at its largest DBH values. For L. novocanariensis, the slope of the curve only slightly slowed down at larger diameters and for $P$. lusitanica the curve was comparable to a linear increase. The growth trajectory of V. rigidum was completely different, and further suggests that this species belongs to a separate group. Although a shade-tolerant species, $V$. rigidum exhibited the same growth trajectory as the two pioneers: an exponential increase in growth with increasing size. We suspect this pattern to be an adaptation to the growth in the understory. Finally, the effects of change in crowding $(\triangle \mathrm{NCI})$ on growth rates were also stronger for the seedling-producing species $H$. excelsa than the sucker-producing species $I$. canariensis and $P$. lusitanica (for which there was no effect at all). The species $L$. novocanariensis was at the boundary between the seedlingproducing species and the sucker-producing species, which is consistent with its 'facultative' strategy relying on both seedlings and suckers.

Based on spatial distributions, marked differences were observed between seedling-producing species and sucker-producing species. The seedling-producing species $\mathrm{H}$. excelsa formed aggregates on a large scale (up to $25 \mathrm{~m}$ ) in both the sapling and adult stands. Moreover, saplings were significantly attracted at about 8-20 m 
around adults which is consistent with the low dispersal abilities provided by its large-sized seeds (Seidler and Plotkin 2006). The two sucker-producing species I. canariensis and P. lusitanica had saplings and especially adults mostly aggregated over shorter distances $(<5 \mathrm{~m})$. A significant attraction at very short distances $(<3 \mathrm{~m})$ was found between adults and saplings for these species, which is consistent with their regeneration based on suckers. This spatial pattern was also observed for L. novocanariensis which relies on both suckers and seedlings for regeneration. This suggests a regeneration strategy relying slightly more on suckers than on seedlings, which is consistent with the abundance of seedlings vs. suckers recorded in the plots. On the other hands, V. rigidum confirmed its singularity compared with the other species, exhibiting a different spatial pattern in each plot, which could further support its own strategy as 'understory species'.

\subsection{Laurel forest natural dynamics}

The characterization of the different ecological groups allows a better understanding of the laurel forest natural dynamics. The differences observed between 1999 and 2015, especially the marked decrease in abundance of pioneer and long-lived pioneer species, point to shifts in species composition towards more advanced successional stages. This was already suggested in earlier studies focusing on species regeneration (Arévalo et al. 1999; Fernández-Lugo et al. 2014) but not described on such a time scale using long-term monitoring data. Since the regeneration of these light-demanding species is dependent on disturbance events, such as tree falls (Elias and Dias 2009), their presence as large adult trees only suggests that the forest is reaching mid-late successional stages (Fernández-Palacios and Arévalo 1998; Dias et al. 2004; Arévalo et al. 2012; Fernández-Lugo et al. 2014). Overall, in 2015 all studied plots showed characteristics of more mature stands with fewer but larger trees compared with 1999 (i.e. a self-thinning process, Westoby 1984). The increase of species richness is also consistent with a forest reaching mid-late successional stages. According to the 'intermediate disturbance hypothesis' (Hubbell et al. 1999; Molino and Sabatier 2001), increase in species richness is caused by shadetolerant species establishing later in the succession process and mixing with pioneer and early shade-tolerant species.

As observed in other studies (Arévalo et al. 2007, 2012), stand structure and species composition differed between the plots in Moquinal (windward) and those in Aguirre (leeward). Plots in Aguirre were richer in species with larger and fewer trees. Earlier studies suggested these differences could be attributed to environmental differences only (Arévalo et al. 1999, 2012). However, using data from other plots located on both windward and leeward sites, another study found more species and larger trees in the windward sites 
(Fernández-Lugo et al. 2014). In addition, although it did not focus on inter-specific aspects, for most species our modeling approach found almost no effects of the plots on tree growth, suggesting only limited differences between sites. Since Moquinal and Aguirre were relatively close to each other and not far away from the central ridge, the orientation windward or leeward may not be the only driver of stand structure and species composition. According to differences in species composition observed between 1999 and 2015, we suggest that stands in Moquinal and in Aguirre are at different successional stages. Indeed, both A. barbujana and P. excelsa, almost exclusively found in Aguirre in 1999, were observed in Moquinal in 2015. The difference in stand structure between both sites also suggests that Moquinal hosts a slightly younger stand with more trees but of smaller size than in Aguirre. It is therefore likely that the shade-tolerant species present in Aguirre will progressively settle in Moquinal as the forest matures.

Table 5: Summary of characteristics of tree species strategies in the laurel forest of Tenerife. Species names were abbreviated using the first two letters of the genus name followed by the first two letters of the species name. See abbreviation section for more details. * Information on growth and spatial distribution was not available for A. barbujana, I. perado, O. foetens, P. excelsa, P. indica and R. glandulosa. WD: wood density.

\begin{tabular}{|c|c|c|c|c|c|c|c|}
\hline $\begin{array}{c}\text { Shade- } \\
\text { tolerance }\end{array}$ & $\begin{array}{c}\text { Reproductive } \\
\text { strategies }\end{array}$ & Strata & Strategies & Species & Functional traits & Growth* & $\begin{array}{c}\text { Spatial } \\
\text { distribution* }\end{array}$ \\
\hline \multirow{2}{*}{$\begin{array}{c}\text { Light- } \\
\text { demanding }\end{array}$} & Seedlings & Canopy & 'Pioneer' & $\begin{array}{l}\text { ERAR } \\
\text { ERSC }\end{array}$ & $\begin{array}{c}\text { Heavy WD - Small } \\
\text { leaves - Small seeds - } \\
\text { Medium DBH95 }\end{array}$ & $\begin{array}{l}\text { Fast growth - } \\
\text { Strong effect of } \\
\text { competition }\end{array}$ & $\begin{array}{l}\text { Aggregation } \\
\text { short to long } \\
\text { distance }\end{array}$ \\
\hline & $\begin{array}{l}\text { Seedlings and } \\
\text { suckers }\end{array}$ & Canopy & $\begin{array}{l}\text { 'Long-lived } \\
\text { pioneer' }\end{array}$ & MOFA & $\begin{array}{c}\text { Heavy WD - Small } \\
\text { leaves - Small seeds - } \\
\text { Large DBH95 } \\
\end{array}$ & $\begin{array}{l}\text { Medium growth - } \\
\text { Strong effect of } \\
\text { competition }\end{array}$ & $\begin{array}{c}\text { Aggregation } \\
\text { short to medium } \\
\text { distance } \\
\end{array}$ \\
\hline \multirow{5}{*}{$\begin{array}{l}\text { Shade- } \\
\text { tolerant }\end{array}$} & \multirow[t]{2}{*}{ Seedlings } & Canopy & 'Itinerant' & $\begin{array}{l}\text { HEEX } \\
\text { PIEX } \\
\text { RHGL }\end{array}$ & $\begin{array}{l}\text { Medium to heavy } \\
\text { WD - Medium to } \\
\text { large leaves - } \\
\text { Medium seeds - } \\
\text { Large DBH95 }\end{array}$ & $\begin{array}{l}\text { Medium growth - } \\
\text { Medium effect of } \\
\text { competition }\end{array}$ & $\begin{array}{l}\text { Aggregation } \\
\text { short to long } \\
\text { distance }\end{array}$ \\
\hline & & Understory & 'Understory' & VIRI & \begin{tabular}{|c|} 
Medium WD - Large \\
leaves - Medium \\
seeds - Small \\
DBH95 \\
\end{tabular} & $\begin{array}{l}\text { Slow growth - } \\
\text { Medium effect of } \\
\text { competition }\end{array}$ & Variable \\
\hline & Suckers & Canopy & 'Persistent' & $\begin{array}{l}\text { ILCA } \\
\text { ILPE } \\
\text { PRLU }\end{array}$ & \begin{tabular}{|} 
Light to medium WD \\
- Medium leaves - \\
Medium seeds - \\
Medium DBH95
\end{tabular} & $\begin{array}{l}\text { Medium growth - } \\
\text { Medium effect of } \\
\text { competition }\end{array}$ & $\begin{array}{l}\text { Aggregation } \\
\text { short distance }\end{array}$ \\
\hline & $\begin{array}{l}\text { Seedlings and } \\
\text { suckers }\end{array}$ & Canopy & 'Facultative' & $\begin{array}{l}\text { APBA } \\
\text { LANO } \\
\text { OCFO } \\
\text { PEIN }\end{array}$ & $\begin{array}{c}\text { Light to Heavy WD - } \\
\text { Large leaves - Large } \\
\text { seeds - Large } \\
\text { DBH95 }\end{array}$ & $\begin{array}{l}\text { Fast growth - } \\
\text { Medium effect of } \\
\text { competition }\end{array}$ & $\begin{array}{l}\text { Aggregation } \\
\text { short distance }\end{array}$ \\
\hline & $\begin{array}{c}\text { Seedlings and } \\
\text { suckers }\end{array}$ & Canopy & $?$ & VIMO & $\begin{array}{c}\text { Heavy WD - } \\
\text { Medium DBH95 }\end{array}$ & $?$ & $?$ \\
\hline
\end{tabular}




\section{Conclusion}

This study has achieved an improved description of tree species strategies in the laurel forest of Tenerife (summarized in Table 5). Consistent with earlier studies, species ordination into different ecological groups seems to rely on (1) their shade-tolerance: light-demanding vs. shade-tolerant species and (2) their reproductive strategies: sexual (i.e. seedlings), asexual (i.e. suckers) or both. We suggest also adding a third aspect to this classification scheme: understory vs. canopy species. These three aspects together have led to six contrasted strategies outlined by consistent stage-specific abundance, functional traits, growth modeling and spatial distributions. The light-demanding group encompasses two different strategies: the two seedling-producing species E. arborea and E. scoparia classified as 'pioneers' and M. faya classified as a 'long-lived pioneer'. In the shade-tolerant group: the seedling-producing species H. excelsa, P. excelsa, and $R$. glandulosa as 'itinerant species' and V. rigidum as 'understory species'; the sucker-producing species $I$. canariensis, I. perado and $P$. lusitanica as 'persistent species'; and A. barbujana, L. novocanariensis, O. foetens and $P$. indica as 'facultative species'. Unfortunately, the strategy of $V$. mocanera remains unclear due to the lack of data for this species. Its presence in only two plots could suggest that this species is one of the latest in the succession process. However, further research needs to be done to validate this hypothesis. More information on growth and spatial patterns would also be needed to fully support the description of ecological strategies of A. barbujana, I. perado, O. foetens, P. excelsa, P. indica and R. glandulosa. Finally, this study also showed that the laurel forest is still maturing in Tenerife and becoming richer in species, which emphasizes the importance of its preservation.

\section{Abbreviations}

CSR : Complete spatial randomness

DBH : Diameter at breast height

APBA : Apollonias barbujana

ERAR : Erica arborea

ERSC : Erica scoparia

HEEX : Heberdenia excelsa

ILCA : Ilex canariensis 
ILPE : Ilex perado

LANO : Laurus novocanariensis

MOFA : Morella faya

OCFO : Ocotea foetens

PEIN : Persea indica

PIEX : Picconia excelsa

PRLU : Prunus lusitanica

RHGL : Rhamnus glandulosa

VIMO : Visnea mocanera

VIRI : Viburnum rigidum

\section{Acknowledgements}

The first author acknowledges funding support from the Région Aquitaine (France) as well as the European Union as part of the Erasmus + internship program. We are grateful to Lukas Rester, Johannes Gebler, Linda Carstens, Zaira Negrín-Pérez and Richard Bigley for assistance with fieldwork. Finally, we record our appreciation to Mark Bloomberg for editing the English as well as six anonymous reviewers for giving useful comments on an earlier version of this paper.

\section{Data availability}

Old and newly-produced data were provided by the authors of this study. However they have not consented to making the original measurement data available as an Appendix to the report, and this must be obtained by request from the authors. 


\section{References}

Ancochea E, Fuster JM, Ibarrola E, Cendrero A, Coello J, Hernán F, Cantagrel JM, Jamond C (1990) Volcanic evolution of the island of Tenerife (Canary Islands) in the light of new K-AR data. Journal of Volcanology and Geothermal Research 44:231-249. https://doi.org/10.1016/0377-0273(90)90019-C

Anten NPR, Schieving F (2010) The role of wood mass density and mechanical constraints in the economy of tree architecture. American Naturalist 175:250-260. https://doi.org/10.1086/649581

Arévalo JR, Delgado JD, Fernández-Palacios JM (2007) Variation in fleshy fruit fall composition in an island laurel forest of the Canary Islands. Acta Oecologica 32:152-160. https://doi.org/10.1016/j.actao.2007.03.014

Arévalo JR, Delgado JD, Fernández-Palacios JM (2008) Changes in plant species composition and litter production in response to roads and trails in the laurel forest of Tenerife (Canary Islands). Plant Biosystems 142:614-622. https://doi.org/10.1080/11263500802410991

Arévalo JR, Delgado JD, Fernández-Palacios JM (2011) Regeneration of potential laurel forest under a native canopy vs. exotic canopy, Tenerife (Canary Islands). Forest Systems 20:255-265. https://doi.org/10.5424/fs/2011202-10921

Arévalo JR, de Nascimento L, Fernández-Lugo S, Méndez J, González-Delgado G, Balguerías E, Pereira Cabral Gomes E, Fernández-Palacios JM (2018) Regeneration dynamics in the laurel forest: changes in species richness and composition. iForest 0:0-0. https://doi.org/10.3832/ifor2580-011

Arévalo JR, Fernández-Palacios JM (1998) Treefall gap characteristics and regeneration in the laurel forest of Tenerife. Journal of Vegetetion Science 9:297-306. https://doi.org/10.2307/3237094

Arévalo JR, Fernández-Palacios JM (2000) Seed bank analysis of tree species in two stands of the Tenerife laurel forest (Canary Islands). Forest Ecology and Management 130:177-185. https://doi.org/10.1016/S03781127(99)00182-6

Arévalo JR, Fernández-Palacios JM (2003) Spatial patterns of trees and juveniles in a laurel forest of Tenerife, Canary Islands. Plant Ecology 165:1-10. https://doi.org/10.1023/A:1021490715660

Arévalo JR, Fernández-Palacios JM (2007) Treefall gaps and regeneration composition in the laurel forest of Anaga (Tenerife): a matter of size? Plant Ecology 188:133-143. https://doi.org/10.1007/s11258-006-9152-1 
Arévalo JR, Fernández-Palacios JM, Palmer MW (1999) Tree regeneration and future dynamics of the laurel forest on Tenerife, Canary Islands. Journal of Vegetation Science 10:861-868. https://doi.org/10.2307/3237311

Arévalo JR, González-Delgado G, Mora B, Fernández-Palacios JM (2012) Compositional and structural differences in two laurel forest stands (windward and leeward) on Tenerife, Canary Islands. Journal of Forest Research 17:184-192. https://doi.org/10.1007/s10310-011-0293-2

Baraloto C, Paine CET, Poorter L, Beauchene J, Bonal D, Domenach AM, Herault B, Patino S, Roggy JC, Chave J (2010) Decoupled leaf and stem economics in rain forest trees. Ecology Letters 13:1338-1347. https://doi.org/10.1111/j.1461-0248.2010.01517.x

Besag J (1977) Contribution to the discussion of Dr. Ripley’s paper. JR Stat. Soc. B 39:193-195.

Brokaw N (1985a) Treefalls, regrowth, and community structure in tropical forests. In: Pickett STA and White PS (Eds) The Ecology of Natural Disturbance and Patch Dynamics, pp 53-68.

Brokaw N (1985b) Gap-phase regeneration in a tropical forest. Ecology 66:682-687. https://doi.org/10.2307/1940529

Carlquist S (1977) Ecological factors in wood evolution: a floristic approach. American journal of botany 64:887-896. http://www.jstor.org/stable/2442382

Chave J, Coomes D, Jansen S, Lewis SL, Swenson NG, Zanne AE (2009) Towards a worldwide wood economics spectrum. Ecology Letters 12:351-366. https://doi.org/10.1111/j.1461-0248.2009.01285.x

Chave J, Muller-Landau HC, Baker TR, Easdale TA, Steege HT, Webb CO (2006) Regional and phylogenetic variation of wood density across 2456 neotropical tree species. Ecological Applications 16:2356-2367. https://doi.org/ 10.1890/1051-0761(2006)016\%5B2356:RAPVOW\%5D2.0.CO;2

Clark DA, Clark DB (1999) Assessing the growth of tropical rain forest trees: issues for forest modeling and management. Ecological Applications 9(3):981-997. https://doi.org/10.2307/2641344

Coomes DA (2006) Challenges to the generality of WBE theory. Trends in Ecology and Evolution 21(11):593596. https://doi.org/10.1016/j.tree.2006.09.002 
del Arco M, González-González R, Garzón-Machado V, Pizarro-Hernández B (2010) Actual and potential natural vegetation on the Canary Islands and its conservation status. Biodiversivity and Conservation 19:30893140. https://doi.org/10.1007/s10531-010-9881-2

Denslow JS (1987) Tropical rainforest gaps and tree species diversity. Annual Review of Ecology and Systematics 18:431-451.

Dias E, Elias RB, Nunes V (2004) Vegetation mapping and nature conservation: a case study in Terceira Island (Azores). Biodiversity and Conservation 13:1519-1539. https://doi.org/10.1023/B:BIOC.0000021326.50170.66

Díaz S, Kattge J, Cornelissen JHC, Wright IJ, Lavorel S, Dray S, Reu B, Kleyer M, Wirth C, Prentice IC, Garnier E, Bönisch G, Westoby M, Poorter H, Reich PB, Moles AT, Dickie J, Gillison AN, Zanne AE, Chave J, Wright SJ, Sheremet'ev SN, Jactel H, Baraloto C, Cerabolini B, Pierce S, Shipley B, Kirkup D, Casanoves F, Joswig JS, Günther A, Falczuk V, Rüger N, Mahecha MD, Gorné LD (2016) The global spectrum of plant form and function. Nature 529:167-171. https://doi.org/10.1038/nature16489

Elias RB, Dias E (2009) Gap dynamics and regeneration strategies in Juniperus-Laurus forests of the Azores Islands. Plant Ecology 200:179-189. https://doi.org/10.1007/s11258-008-9442-X

Favrichon V (1994) Classification des espèces arborées en groupes fonctionnels en vue de la réalisation d'un modèle de dynamique de peuplement en forêt guyanaise. Revue d'Ecologie Terre et Vie 49:379-402.

Fernández-Lugo S, de Nascimento L, Méndez J, González-Delgado G, Gomes EPC, Rüdiger O, Arévalo JR, Fernández-Palacios JM (2014) Seedling survival patterns in Macaronesian laurel forest: a long-term study in Tenerife (Canary Islands). Forestry: An International Journal of Forest Research 88(1):121-130. https://doi.org/10.1093/forestry/cpu035

Fernández-Palacios JM (2009) Laurisilvas macaronésicas (Laurus, Ocotea) (*). In VV.AA., Bases ecológicas preliminares para la conservación de los tipos de hábitat de interés comunitario en Espana. Ministerio de Medio Ambiente, y Medio Rural y Marino.

Fernández-Palacios JM, Arévalo JR (1998) Regeneration strategies of tree species in the laurel forest of Tenerife (The Canary Islands). Plant Ecology 137:21-29. https://doi.org/10.1023/A:1008000330184

Fernández-Palacios JM, Arévalo JR, González-Delgado G, Delgado JD, Rüdiger O (2004) Estrategias de regeneración en la laurisilva. Makaronesia 6:90-101. 
Fernández-Palacios JM, Arévalo JR, Balguerías E, Barone R, de Nascimento L, Delgado JD, Elias RB, Fernández-Lugo S, Méndez J, Naranjo A, Sequeira M, Otto R (2017) La Laurisilva. Canarias, Madeira y Azores. Macaronesia. Editorial, Santa Cruz de Tenerife.

Gavin DG, Peart DR (1997) Spatial structure and regeneration of Tetramerista glabra in peat swamp rain forest in Indonesian Borneo. Plant Ecology 131:223-231. https://doi.org/10.1023/A:1009771519028

Getzin S, Wiegand T, Wiegand K, He F (2008) Heterogeneity influences spatial patterns and demographics in forest stands. Journal of Ecology 96(4):807-820. https://doi.org/10.1111/j.1365-2745.2008.01377.x

Goreaud F, Pélissier R (1999) On explicit formulas of edge effect correction for Ripley’s K-function. Journal of Vegetation Science 10:433-438. https://doi.org/10.2307/3237072

Goreaud F, Pélissier R (2003) Avoiding misinterpretation of biotic interactions with the intertype K12-function: population independence vs. random labelling hypotheses. Journal of Vegetation Science 14:681-692. https://doi.org/10.1111/j.1654-1103.2003.tb02200.x

Guimarāes A, Olmeda C (2008) Management of Natura 2000 habitat. $9360 *$ Macaronesian laurel forests (Laurus, Ocotea). European Commission.

Hacke UG, Sperry JS, Pockman WT, Davis SD, McCulloh KA (2001) Trends in wood density and structure are linked to prevention of xylem implosion by negative pressure. Oecologia 126:457-461. https://doi.org/10.1007/s004420100628

Herault B, Bachelot B, Poorter L, Rossi V, Bongers F, Chave J, Paine C, Wagner F, Baraloto C (2011) Functional traits shape ontogenetic growth trajectories of rain forest tree species. Journal of Ecology 99(6):14311440. https://doi.org/10.1111/j.1365-2745.2011.01883.x.

Herault B, Ouallet J, Blanc L, Wagner F, Baraloto C (2010) Growth responses of neotropical trees to logging gaps. Journal of Applied Ecology 47(4):821-831. https://doi.org/10.1111/j.1365-2664.2010.01826.x.

Hirose T, Werger M (1987) Maximizing daily canopy photosynthesis with respect to the leaf nitrogen allocation pattern in the canopy. Oecologia 72:520-526. https://doi.org/10.1007/BF00378977 
Hubbell SP, Foster RB, O’Brien ST, Harms K, Condit R,Wechsler B, Wright SJ, De Lao SL (1999) Light-gap disturbances, recruitment limitation, and tree diversity in a neotropical forest. Science 283:554-557. https://doi.org/10.1126/science.283.5401.554

Kämmer F (1974) Klima und vegetation auf Tenerife, besonders in Hinblick auf den Nebelniedershlag. Scripta Geobotanica 7:1-78.

King DA, Davies SJ, Noor NSM (2006a) Growth and mortality are related to adult tree size in a Malaysian mixed dipterocarp forest. Forest Ecology and Management 223:152-158. https://doi.org/10.1016/j.foreco.2005.10.066

King DA, Davies SJ, Tan S, Noor NSM (2006b) The role of wood density and stem support costs in the growth and mortality of tropical trees. Journal of Ecology 94:670-680. https://doi.org/10.1016/j.foreco.2005.10.066

Laliberté E, Legendre P (2010) A distance-based framework for measuring functional diversity from multiple traits. Ecology 91:299-305. https://doi.org/10.1890/08-2244.1

Laliberté E, Legendre P, Shipley B (2014) FD: measuring functional diversity from multiple traits, and other tools for functional ecology. R package version 1.0-12.

Lasky JR, Bachelot B, Muscarella R, Schwartz N, Forero-Montaña J, Nytch CJ, Swenson NG, Thompson J, Zimmermann JK, Uriarte M (2015) Ontogenetic shifts in trait-mediated mechanisms of plant community assembly. Ecology 96:2157-2169. https://doi.org/10.1890/14-1809.1

Legendre P, Legendre L (1998) Numerical ecology (2nd english ed.) Elsevier Science bv. Amsterdam, The Netherlands.

Lotwick HW, Silverman BW (1982) Methods for analysing spatial processes of several types of points. Journal of the Royal Statistical Society. Series B (Methodological) 44: 406-413. http://www.jstor.org/stable/2345499

Lugo AE, Scatena FN (1996) Background and catastrophic tree mortality in tropical moist, wet and rain forests. Biotropica 28:585-599. https://doi.org/10.2307/2389099

Lusk CH (1999) Long-lived light-demanding emergents in southern temperate forests: the case of Weinmannia trichosperma (Cunoniaceae) in Chile. Plant Ecology 140:111-115. https://doi.org/10.1023/A:1009764705942 
Markesteijn L, Poorter L, Bongers F, Paz H, Sack L (2011) Hydraulics and life-history of tropical dry forest tree species: coordination of species drought- and shade-tolerance. New Phytologist 191:480-495. https://doi.org/10.1111/j.1469-8137.2011.03708.x

Meinzer FC (2003) Functional convergence in plant responses to the environment. Oecologia 134:1-11. https://doi.org/10.1007/s00442-002-1088-0

Moles AT, Falster DS, Leishman MR, Westoby M (2004) Small seeded species produce more seeds per square metre of canopy per year, but not per individual per lifetime. Journal of Ecology 92:384-396. https://doi.org/10.1111/j.0022-0477.2004.00880.x

Molino J-F, Sabatier D (2001) Tree diversity in tropical rain forests: a validation of the intermediate disturbance hypothesis. Science 294:1702-1704. https://doi.org/10.1126/science.1060284

Morales G, Pérez R (2000) Gran Atlas Temático de Canarias. Editorial Interinsular Canaria.

Muller-Landau HC (2004) Interspecific and Inter-site Variation in Wood Specific Gravity of Tropical Trees1. Biotropica 36:20-32. https://doi.org/10.1646/02119

Muller-Landau HC, Condit RS, Harms KE, Marks CO, Thomas SC, Bunyavejchewin S, Chuyong G, Co L, Davies S, Foster R, et al. (2006) Comparing tropical forest tree size distributions with the predictions of metabolic ecology and equilibrium models. Ecology Letters 9(5):589-602. https://doi.org/10.1111/j.14610248.2006.00915.x

Nakagawa S, Schielzeth H (2013) A general and simple method for obtaining R2 from generalized linear mixedeffects models. Methods in Ecology and Evolution 4:133-142. https://doi.org/10.1111/j.2041210x.2012.00261.x.

Niiyama K, Rahman KA, Iida S, Kimura K, Azizi R, Appanah S (1999) Spatial patterns of common tree species relating to topography, canopy gaps and understorey vegetation in a hill dipterocarp forest at Semangkok Forest Reserve, Peninsular Malaysia. Journal of Tropical Forest Science 11: 731-745. http://www.jstor.org/stable/43582322

Ohsawa M, Nitta I (1999) Leaf traits and stomata of evergreen broad-leaved trees in Anaga cloud forest. In: Ohsawa M, Wildpret de la Torre W, Del Árco M (eds) Anaga cloud forest: A comparative study on evergreen 
broadleaved forests and trees of the Canary Islands and Japan, Chiba (Laboratory of Ecology, Chiba University), pp 223-246.

Parsons JJ (1981) Human influence on the pine and laurel forest of the Canary Islands. Geographical Review 71:253-271. http://www.jstor.org/stable/214699

Pélissier R, Goreaud F (2015) Ads package for R: a fast unbiased implementation of the K-function family for studying spatial point patterns in irregular-shaped sampling windows. Journal of Statistical Software 63:1-18.

Perez-Harguindeguy N, Diaz S, Garnier E, Lavorel S, Poorter H, Jaureguiberry P, Cornwell WK, Craine JM, et al. (2013) New handbook for standardised measurement of plant functional traits worldwide. Australian Journal of Botany 61:167-234. https://doi.org/10.1071/BT12225

Poorter H, Niinemets U, Poorter L, Wright IJ, Villar R (2009) Causes and consequences of variation in leaf mass per area (LMA): a meta-analysis. New Phytologist 182:565-588. https://doi.org/10.1111/j.14698137.2009.02830.x

Poorter L, Bongers L, Bongers F (2006) Architecture of 54 moist-forest tree species: traits, trade-offs, and functional groups. $\quad$ Ecology $\quad$ 87(5):1289-1301. https://doi.org/10.1890/00129658(2006)87[1289:AOMTST]2.0.CO;2

Poorter L, Bongers F, Sterck FJ, Wöll H (2005) Beyond the regeneration phase: differentiation of height-light trajectories among tropical tree species. Journal of Ecology 93(2):256-267. https://doi.org/10.1111/j.13652745.2004.00956.x

Pupo-Correia AMC (2016) Evolution of the Landscape of Madeira Island. Long-term vegetation dynamics. PhD Thesis, Madeira University.

R Core Team (2015) R: A Language and Environment for Statistical Computing. R Foundation for Statistical Computing, Vienna, Austria.

Reich PB, Tjoelker MG, Machado J-L, Oleksyn J (2006) Universal scaling of respiratory metabolism, size and nitrogen in plants. Nature 439(7075):457-461. https://doi.org/10.1038/nature04282

Ripley BD (1977) Modeling spatial patterns (with discussion). Journal of the Royal Statistical Society. Series B (Methodological) 39:172-212. http://www.jstor.org/stable/2984796 
Ripley BD (1981) Spatial statistics. Wiley, New York, NY, US.

Rowe N, Speck $T$ (2005) Plant growth forms: an ecological and evolutionary perspective. New Phytologist 166:61-72. https://doi.org/10.1111/j.1469-8137.2004.01309.x

Santiago LS, Goldstein G, Meinzer FC, Fisher JB, Machado K, Woodruff D, Jones T (2004a) Leaf photosynthetic traits scale with hydraulic conductivity and wood density in Panamanian forest canopy trees. Oecologia 140:543-550. https://doi.org/10.1007/s00442-004-1624-1

Santiago LS, Kitajima K, Wright SJ, Mulkey SS (2004b) Coordinated changes in photosynthesis, water relations and leaf nutritional traits of canopy trees along a precipitation gradient in lowland tropical forest. Oecologia 139:495-502. https://doi.org/10.1007/s00442-004-1542-2

Santos A (1990) Bosques de laurisilva en la región macaronésica. Colección Naturaleza y Medio Ambiente, No. 49, Council of Europe, Strasbourg.

Seidler TG, Plotkin JB (2006) Seed dispersal and spatial pattern in tropical trees. PLoS Biology 4:e344. https://doi.org/10.1371/journal.pbio.0040344

Suzuki E (1999) Diversity in specific gravity and water content of wood among Bornean tropical rainforest trees. Ecological Research 14:211-224. https://doi.org/10.1046/j.1440-1703.1999.143301.x

Swaine MD, Whitmore TC (1988) On the definition of ecological species groups in tropical rain forests. Plant Ecology 75:81-86. https://doi.org/10.1007/BF00044629

ter Steege H., Hammond DS (2001) Character convergence, diversity, and disturbance in tropical rain forest in Guyana. Ecology 82(11):3197-3212. https://doi.org/10.1890/0012-9658(2001)082[3197:CCDADI]2.0.CO;2

Tyree MT, Sperry JS (1989) Vulnerability of xylem to cavitation and embolism. Annual Review of Plant Biology 40:19-36. https://doi.org/10.1146/annurev.pp.40.060189.000315

Uhl C, Jordan CF (1984) Succession and nutrient dynamics following forest cutting and burning in Amazonia. Ecology 65:1476-1490. https://doi.org/10.2307/1939128

Westoby M (1984) The self-thinning rule. In: Advances in ecological research (Vol. 14), Academic Press, pp $167-225$. 
Westoby M (1998) A leaf-height-seed (LHS) plant ecology strategy scheme. Plant and Soil 199:21-227. https://doi.org/10.1023/A:1004327224729

Westoby M, Falster DS, Moles AT, Vesk PA, Wright IJ (2002) Plant ecological strategies: some leading dimensions of variation between species. Annual Review of Ecology and Systematics 33:125-159. https://doi.org/10.1146/annurev.ecolsys.33.010802.150452

Whitmore TC (1989) Canopy gaps and the two major groups of forest trees. Ecology 70:536-538. http://www.jstor.org/stable/1940195

Wright SJ, Muller-Landau HC, Condit R, Hubbell SP (2003) Gap-dependent recruitment, realized vital rates, and size distributions of tropical trees. Ecology 84:3174-3185. https://doi.org/ 10.1890/02-0038

Zuur AF, Ieno EN, Walker NJ, Saveliev AA, Smith GM (2009) Mixed effects models and extensions in ecology with R, Springer, New York. 
Appendix A Description of the six study plots in the laurel forest of Anaga, Tenerife.

\begin{tabular}{lcccccc}
\hline Variable & Moq. 1 & Moq. 2 & Moq. 3 & Agu. 1 & Agu. 2 & Agu. 3 \\
\hline \hline Altitude $(\mathrm{m})$ & 775 & 850 & 820 & 850 & 925 & 810 \\
Orientation & NNE & WNW & NW & SE & S & S \\
Slope $\left({ }^{\circ}\right)$ & 15 & 10 & 30 & 20 & 40 & 30 \\
Canopy cover $(\%)$ & 90 & 95 & 95 & 95 & 95 & 95 \\
Understory cover $(\%)$ & 15 & 20 & 15 & 40 & 60 & 45 \\
Rock cover $(\%)$ & 1 & 5 & 5 & 1 & 10 & 15 \\
\hline
\end{tabular}

\section{Appendix B The 12 key functional traits used in our study}

\begin{tabular}{|c|c|c|c|c|c|c|c|c|c|c|c|c|}
\hline \multirow[b]{2}{*}{ Species } & \multirow{2}{*}{$\begin{array}{c}\text { Stem } \\
\text { Wood } \\
\text { density } \\
\left(\mathrm{g} / \mathrm{cm}^{3}\right)\end{array}$} & \multicolumn{4}{|c|}{$\begin{array}{c}\text { Leaf } \\
\text { (Ohsawa and Nitta 1999) }\end{array}$} & \multicolumn{6}{|c|}{$\begin{array}{c}\text { Fruit/Seed } \\
\text { (Arévalo et al. 2007) }\end{array}$} & \multirow{2}{*}{\begin{tabular}{|c|} 
Size \\
$\begin{array}{c}\text { DBH95 } \\
(\mathrm{cm})\end{array}$
\end{tabular}} \\
\hline & & $\begin{array}{c}\text { Leaf } \\
\text { area } \\
\left(\mathrm{cm}^{2}\right) \\
\end{array}$ & $\begin{array}{c}\text { Leaf } \\
\text { mass } \\
\left(\mathrm{g} / \mathrm{m}^{2}\right)\end{array}$ & $\begin{array}{c}\text { Lamina } \\
\text { thickness } \\
(\mu \mathrm{m})\end{array}$ & $\begin{array}{c}\text { Stomata } \\
\text { density } \\
\left(\mathrm{nb} / \mathrm{mm}^{2}\right)\end{array}$ & $\begin{array}{c}\text { Fruit } \\
\text { length } \\
(\mathrm{mm})\end{array}$ & $\begin{array}{c}\text { Fruit } \\
\text { diameter } \\
(\mathrm{mm})\end{array}$ & $\begin{array}{c}\text { Fruit } \\
\text { weight } \\
\text { (g) }\end{array}$ & $\begin{array}{c}\text { Seed } \\
\text { length } \\
(\mathrm{mm}) \\
\end{array}$ & $\begin{array}{c}\text { Seed } \\
\text { diameter } \\
(\mathrm{mm})\end{array}$ & $\begin{array}{c}\text { Seed } \\
\text { weight } \\
(\mathrm{g})\end{array}$ & \\
\hline APBA & 0.73 & 45 & - & - & - & 18.07 & 13.60 & 0.85 & 15.45 & 10.41 & 0.51 & 33.90 \\
\hline ERAR & 0.62 & 0.05 & - & - & - & - & - & - & - & 0.62 & - & 31.20 \\
\hline ERSC & 0.72 & 0.03 & - & - & - & - & - & - & - & 0.60 & - & 21.80 \\
\hline HEEX & 0.62 & 25.30 & 92.04 & 161.72 & 317.06 & 8.19 & 10.79 & 0.15 & 6.53 & 7.16 & 0.10 & 33.00 \\
\hline ILCA & 0.64 & 13.50 & 137. 27 & 238 & 155.20 & - & 10.44 & 0.26 & 7.12 & 3.47 & 0.03 & 17.50 \\
\hline ILPE & 0.55 & 26.50 & 167.81 & 296.80 & 176.39 & - & 10.63 & 0.62 & 6.54 & 3.69 & 0.06 & 34.80 \\
\hline LANO & 0.54 & 18.30 & 130.33 & 194.10 & 288.98 & 16.09 & 12.16 & 1.54 & 13.74 & 10.22 & 0.84 & 21.90 \\
\hline MOFA & 0.64 & 7.90 & 88.66 & 168.20 & 195.12 & - & 7.76 & 0.25 & 0.081 & 4.69 & 0.04 & 43.60 \\
\hline OCFO & 0.51 & 35.30 & 82.75 & 163.60 & 215.82 & 21.11 & 14.52 & 0.72 & 17.64 & 11.37 & 0.38 & 92.80 \\
\hline PEIN & 0.47 & 53 & 84.60 & 170 & 150.77 & 18.60 & 12.71 & 1.84 & 16.93 & 10.74 & 1.16 & 42.70 \\
\hline PIEX & 0.71 & 25.30 & 105.81 & 185.33 & 328.15 & 18.91 & 12.41 & 0.66 & 17.8 & 8.74 & 0.33 & 57.00 \\
\hline PRLU & 0.55 & 25.40 & 108.56 & 228 & 280.12 & 11.57 & 11.10 & 0.17 & 7.40 & 5.75 & 0.05 & 21.80 \\
\hline RHGL & 0.61 & 16.90 & 60.13 & 97.40 & 195.85 & 8.63 & 8.70 & 0.13 & 6.69 & 4.56 & 0.03 & 34.30 \\
\hline VIMO & 0.76 & - & - & - & - & 10.43 & 8.81 & 0.21 & - & - & - & 22.60 \\
\hline VIRI & 0.63 & 43.20 & 86.05 & 133.08 & 209.90 & 8.73 & 5.27 & 0.13 & 8.23 & 4.47 & 0.07 & 8.90 \\
\hline
\end{tabular}

the species name. See abbreviation section for more details. 


\section{Appendix C Growth modeling of 8 laurel forest species}

Model selections were performed using the difference in crowding index between 1999 and $2015(\triangle N C I)$, measured within different distances (d). Parameters $D$ and $D 2$ remained the same whatever the distance. We first controlled for collinearity between $D$ and $\triangle N C I$ using the variance inflation factors (VIF). The remaining variables were finally separately added and kept if they improved the model support (lower AIC). Growth model: final model for each distance with variables in the order they were selected using the AIC. AIC: final AIC of the model after both selections (using VIF and AIC). Marginal $\mathrm{R}^{2}$ : fixed effects only. Conditional $\mathrm{R}^{2}$ : fixed and random effects. Chosen final models and distances are shown in bold and were selected based on the AIC values. $D$ : $D B H / D B H 95$ and $D 2:(D B H / D B H 95)^{2}$.

Table C.1 : Erica arborea

\begin{tabular}{ccccc}
\hline $\mathbf{d}(\mathbf{m})$ & Growth model & AIC & Marg. $\mathbf{R}^{\mathbf{2}}$ & Cond. $^{\mathbf{2}}$ \\
\hline \hline $\mathbf{2 . 5}$ & $\boldsymbol{D}+\Delta \boldsymbol{N C I}$ & $\mathbf{- 3 7 . 8 3}$ & $\mathbf{0 . 5 8}$ & $\mathbf{0 . 5 8}$ \\
5 & $D+\Delta N C I$ & -33.18 & 0.57 & 0.58 \\
7.5 & $D+\Delta N C I$ & -27.48 & 0.55 & 0.56 \\
10 & $D+\Delta N C I$ & -25.19 & 0.55 & 0.56 \\
12.5 & $D+\Delta N C I$ & -24.18 & 0.54 & 0.56 \\
15 & $D+\Delta N C I$ & -20.20 & 0.53 & 0.55 \\
17.5 & $D+\Delta N C I$ & -18.46 & 0.53 & 0.55 \\
20 & $D+\Delta N C I$ & -17.92 & 0.53 & 0.54 \\
\hline
\end{tabular}

Table C.2 : Erica scoparia

\begin{tabular}{ccccc}
\hline $\mathbf{d}(\mathbf{m})$ & Growth model & AIC & Marg. $\mathbf{R}^{\mathbf{2}}$ & Cond. $^{\mathbf{2}}$ \\
\hline \hline $\mathbf{2 . 5}$ & $\Delta \boldsymbol{N} \boldsymbol{C I}+\boldsymbol{D}$ & $\mathbf{5 . 3 1}$ & $\mathbf{0 . 6 0}$ & $\mathbf{0 . 6 4}$ \\
5 & $D+\Delta N C I$ & 6.20 & 0.60 & 0.63 \\
7.5 & $D+\Delta N C I$ & 8.04 & 0.58 & 0.61 \\
10 & $D+\Delta N C I$ & 9.32 & 0.57 & 0.60 \\
12.5 & $D+\Delta N C I$ & 9.72 & 0.56 & 0.60 \\
15 & $D+\Delta N C I$ & 9.74 & 0.56 & 0.60 \\
17.5 & $D+\Delta N C I$ & 9.99 & 0.56 & 0.60 \\
20 & $D+\Delta N C I$ & 10.71 & 0.55 & 0.60 \\
\hline
\end{tabular}

Table C.3 : Heberdenia excelsa

\begin{tabular}{clccc}
\hline $\mathbf{d}(\mathbf{m})$ & Growth model & AIC & Marg. $\mathbf{R}^{\mathbf{2}}$ & Cond. $^{\mathbf{2}}$ \\
\hline \hline 2.5 & $D+D 2+\Delta N C I$ & -65.09 & 0.45 & 0.46 \\
5 & $D+D 2+\Delta N C I$ & -65.76 & 0.46 & 0.46 \\
7.5 & $D+D 2+\Delta N C I$ & -66.43 & 0.46 & 0.47 \\
10 & $D+D 2+\Delta N C I$ & -67.85 & 0.47 & 0.47 \\
12.5 & $D+D 2+\Delta N C I$ & -67.88 & 0.47 & 0.48 \\
15 & $D+D 2+\Delta N C I$ & -67.71 & 0.47 & 0.47 \\
17.5 & $D+D 2+\Delta N C I$ & -68.65 & 0.47 & 0.48 \\
$\mathbf{2 0}$ & $\boldsymbol{D}+\boldsymbol{D} 2+\Delta \boldsymbol{N C I}$ & $\mathbf{- 7 0 . 1 3}$ & $\mathbf{0 . 4 8}$ & $\mathbf{0 . 4 8}$ \\
\hline
\end{tabular}

Table C.4 : Ilex canariensis

\begin{tabular}{ccccc}
\hline $\mathbf{d}(\mathbf{m})$ & Growth model & AIC & Marg. $\mathbf{R}^{\mathbf{2}}$ & Cond. $^{\mathbf{2}}$ \\
\hline \hline $\mathbf{2 . 5}$ & $\boldsymbol{D}+\Delta \boldsymbol{N C I}+\boldsymbol{D 2}$ & $\mathbf{- 6 5 3 . 1 4}$ & $\mathbf{0 . 4 2}$ & $\mathbf{0 . 4 7}$ \\
5 & $D+D 2+\Delta N C I$ & -648.31 & 0.41 & 0.46 \\
7.5 & $D+D 2+\Delta N C I$ & -650.11 & 0.41 & 0.46 \\
10 & $D+D 2+\Delta N C I$ & -647.52 & 0.41 & 0.45 \\
12.5 & $D+D 2+\Delta N C I$ & -645.38 & 0.40 & 0.45 \\
15 & $D+D 2+\Delta N C I$ & -643.47 & 0.40 & 0.45 \\
17.5 & $D+D 2+\Delta N C I$ & -645.07 & 0.40 & 0.45 \\
20 & $D+D 2+\Delta N C I$ & -643.42 & 0.40 & 0.45 \\
\hline
\end{tabular}


Table C.5 : Laurus novocanariensis

\begin{tabular}{ccccc}
\hline $\mathbf{d}(\mathbf{m})$ & Growth model & AIC & Marg. $\mathbf{R}^{\mathbf{2}}$ & Cond. $^{\mathbf{2}}$ \\
\hline \hline 2.5 & $D+\Delta N C I+D 2$ & -329.03 & 0.64 & 0.66 \\
$\mathbf{5}$ & $\boldsymbol{D}+\Delta \boldsymbol{N C I}+\boldsymbol{D} \mathbf{2}$ & $\mathbf{- 3 3 0 . 7 0}$ & $\mathbf{0 . 6 4}$ & $\mathbf{0 . 6 6}$ \\
7.5 & $D+D 2+\Delta N C I$ & -327.05 & 0.64 & 0.66 \\
10 & $D+D 2+\Delta N C I$ & -325.04 & 0.64 & 0.66 \\
12.5 & $D+D 2+\Delta N C I$ & -324.06 & 0.64 & 0.66 \\
15 & $D+D 2+\Delta N C I$ & -322.88 & 0.63 & 0.66 \\
17.5 & $D+D 2+\Delta N C I$ & -324.04 & 0.64 & 0.66 \\
20 & $D+D 2+\Delta N C I$ & -324.76 & 0.64 & 0.66 \\
\hline
\end{tabular}

Table C.6 : Morella faya

\begin{tabular}{ccccc}
\hline $\mathbf{d}(\mathbf{m})$ & Growth model & AIC & Marg. $\mathbf{R}^{\mathbf{2}}$ & Cond. $^{\mathbf{2}}$ \\
\hline $\mathbf{2 . 5}$ & $\boldsymbol{D}+\Delta \boldsymbol{N C I}$ & $\mathbf{- 1 1 . 5 6}$ & $\mathbf{0 . 4 2}$ & $\mathbf{0 . 5 6}$ \\
5 & $D+\Delta N C I$ & -11.15 & 0.42 & 0.57 \\
7.5 & $D+\Delta N C I$ & -11.39 & 0.43 & 0.60 \\
10 & $D+\Delta N C I$ & -10.56 & 0.42 & 0.60 \\
12.5 & $D+\Delta N C I$ & -10.13 & 0.42 & 0.61 \\
15 & $D+\Delta N C I$ & -8.20 & 0.41 & 0.58 \\
17.5 & $D+\Delta N C I$ & -8.31 & 0.41 & 0.59 \\
20 & $D+\Delta N C I$ & -8.16 & 0.41 & 0.60 \\
\hline
\end{tabular}

Table C.7 : Prunus lusitanica

\begin{tabular}{ccccc}
\hline d (m) & Growth model & AIC & Marg. $\mathbf{R}^{2}$ & Cond. R$^{\mathbf{2}}$ \\
\hline \hline 2.5 & $D+D 2$ & -299.60 & 0.51 & 0.54 \\
5 & $D+D 2$ & -299.60 & 0.51 & 0.54 \\
7.5 & $D+D 2$ & -299.60 & 0.51 & 0.54 \\
10 & $D+D 2$ & -299.60 & 0.51 & 0.54 \\
12.5 & $D+D 2$ & -299.60 & 0.51 & 0.54 \\
15 & $D+D 2$ & -299.60 & 0.51 & 0.54 \\
17.5 & $D+D 2$ & -299.60 & 0.51 & 0.54 \\
20 & $D+D 2$ & -299.60 & 0.51 & 0.54 \\
\hline
\end{tabular}

Table C.8 : Viburnum rigidum

\begin{tabular}{ccccc}
\hline $\mathbf{d}(\mathbf{m})$ & Growth model & AIC & Marg. $\mathbf{R}^{\mathbf{2}}$ & Cond. $^{\mathbf{2}}$ \\
\hline $\mathbf{2 . 5}$ & $\Delta \boldsymbol{N C I}+\boldsymbol{D 2}$ & $\mathbf{- 8 6 . 6 3}$ & $\mathbf{0 . 3 5}$ & $\mathbf{0 . 3 5}$ \\
5 & $\Delta N C I+D 2$ & -83.57 & 0.31 & 0.31 \\
7.5 & $D 2+\Delta N C I$ & -81.93 & 0.28 & 0.28 \\
10 & $D 2+\Delta N C I$ & -78.94 & 0.24 & 0.24 \\
12.5 & $D 2+\Delta N C I$ & -78.97 & 0.24 & 0.24 \\
15 & $D 2+\Delta N C I$ & -78.06 & 0.23 & 0.23 \\
17.5 & $D 2+\Delta N C I$ & -77.66 & 0.22 & 0.22 \\
20 & $D 2+\Delta N C I$ & -77.45 & 0.22 & 0.22 \\
\hline
\end{tabular}



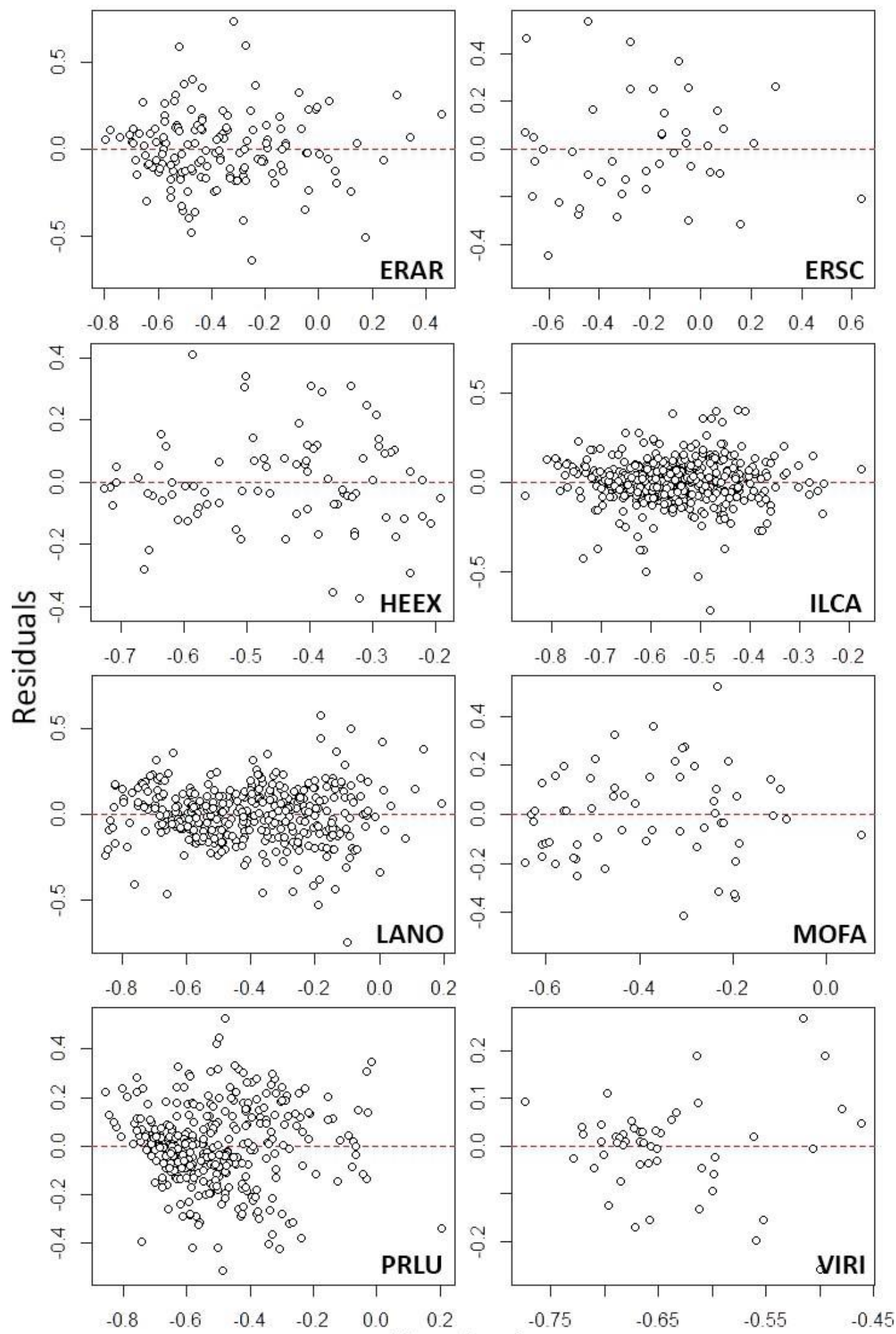

Fitted values

Figure C.1 : Fitted values vs residuals in the final growth models of eight laurel forest species. Species names were abbreviated using the first two letters of the genus name followed by the first two letters of the species name. See abbreviation section for more details. 


\section{Appendix D Spatial distribution and spatial pattern analysis of 8 laurel forest species}

\section{Erica arborea}
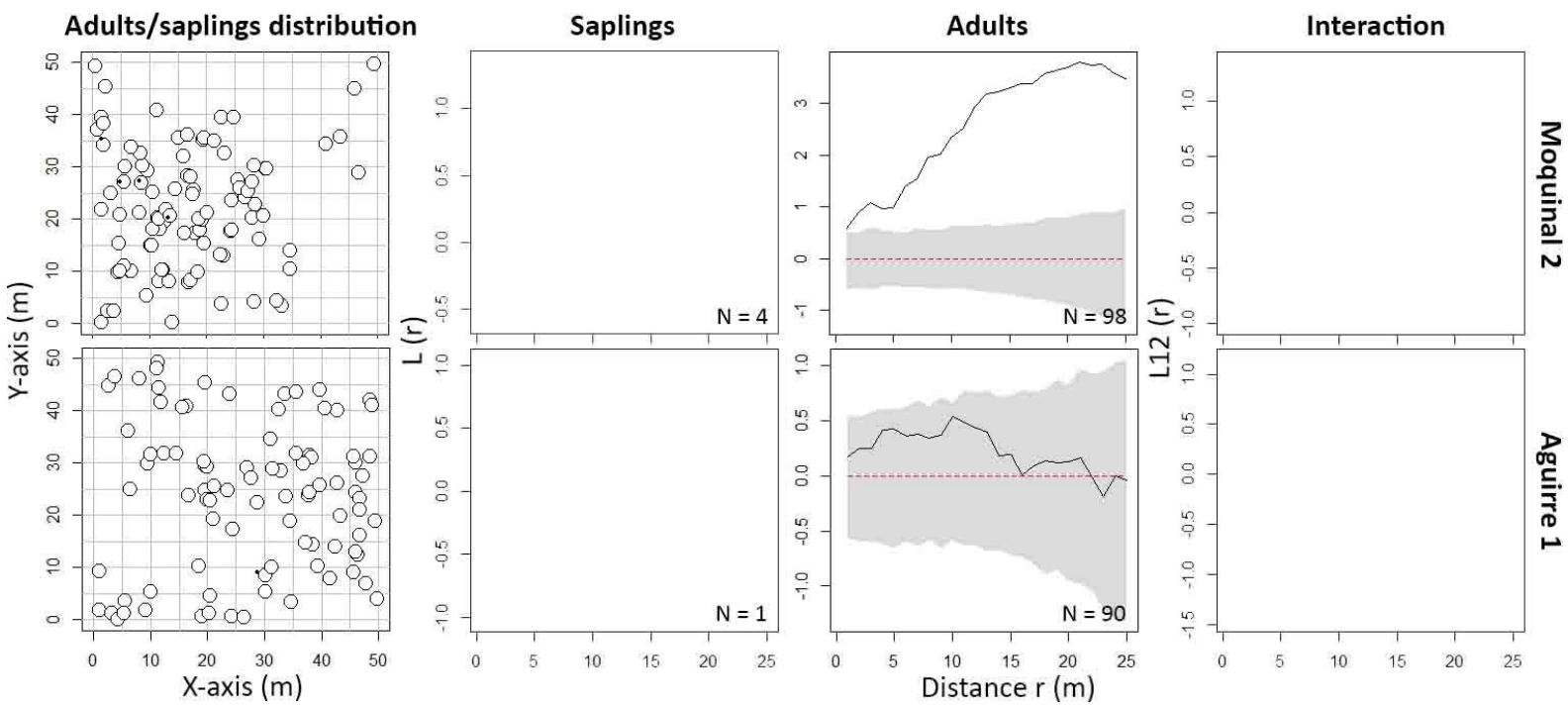

Figure D.1: Spatial distribution and spatial pattern analysis of Erica arborea in Moquinal 2 and Aguirre 1. Black circles: saplings, large open circles: adults. Spatial analysis was not carried out in these plots for saplings and in the other plots for both adults and saplings due to the low number of individuals. Black curves represent observed values of the index and grey area represent the $C I_{99 \%}$ limits of the null hypothesis. $\mathrm{N}$ is the number of points in the plot.

\section{Erica scoparia}
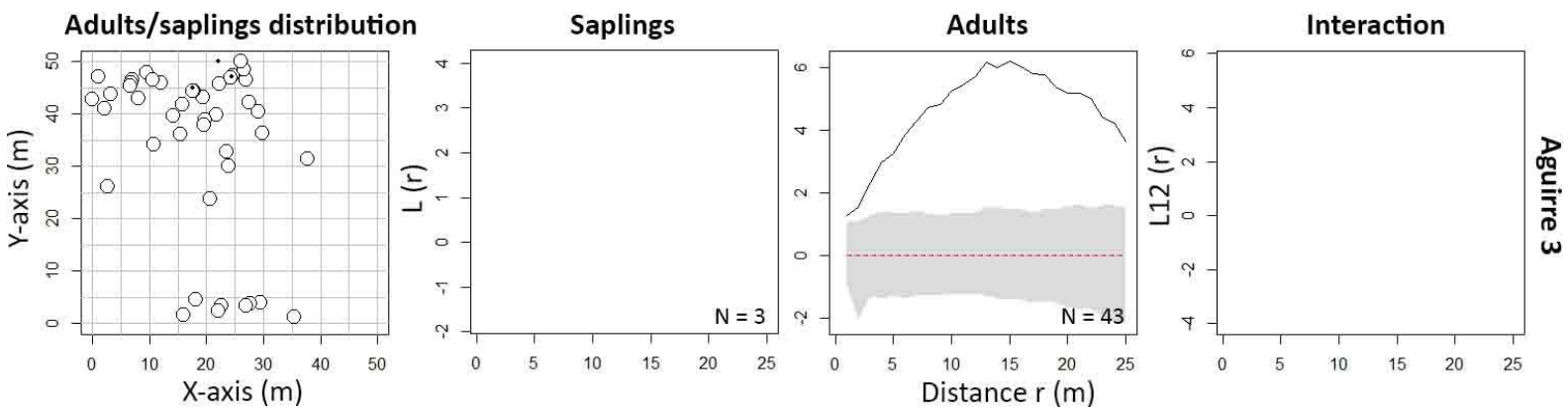

Figure D.2: Spatial distribution and spatial pattern analysis of Erica scoparia in Aguirre 3. Black circles: saplings, large open circles: adults. Spatial analysis was not carried out in this plot for saplings and in the other plots for both adults and saplings due to the low number of individuals. Black curves represent observed values of the index and grey area represent the $C I_{99 \%}$ limits of the null hypothesis. $\mathrm{N}$ is the number of points in the plot. 


\section{Heberdenia excelsa}
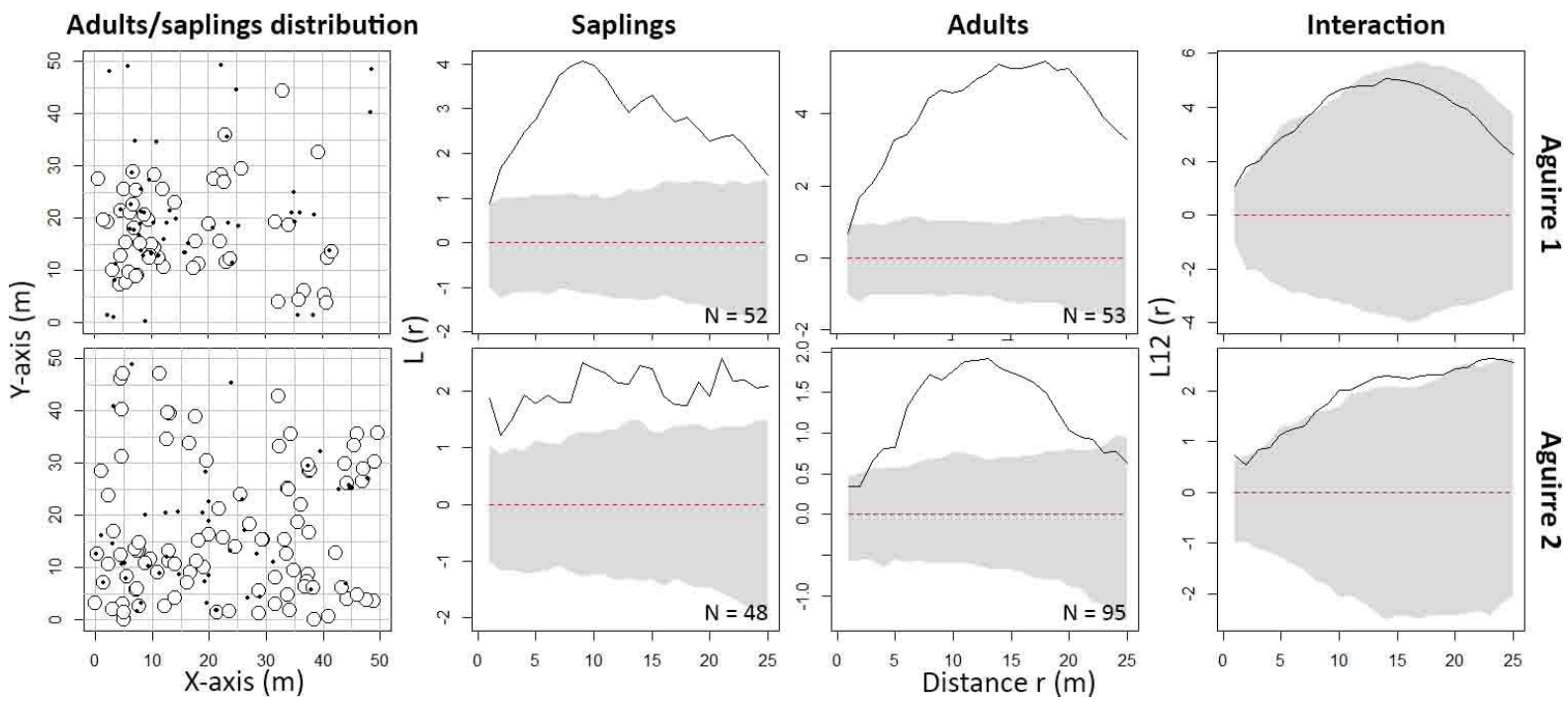

Figure D.3: Spatial distribution and spatial pattern analysis of Heberdenia excelsa in Aguirre 1 and 2. Black circles: saplings, large open circles: adults. Spatial analysis was not carried out in the other plots due to the low number of individuals. Black curves represent observed values of the index and grey area represent the $C I_{99 \%}$ limits of the null hypothesis. $\mathrm{N}$ is the number of points in the plot. 


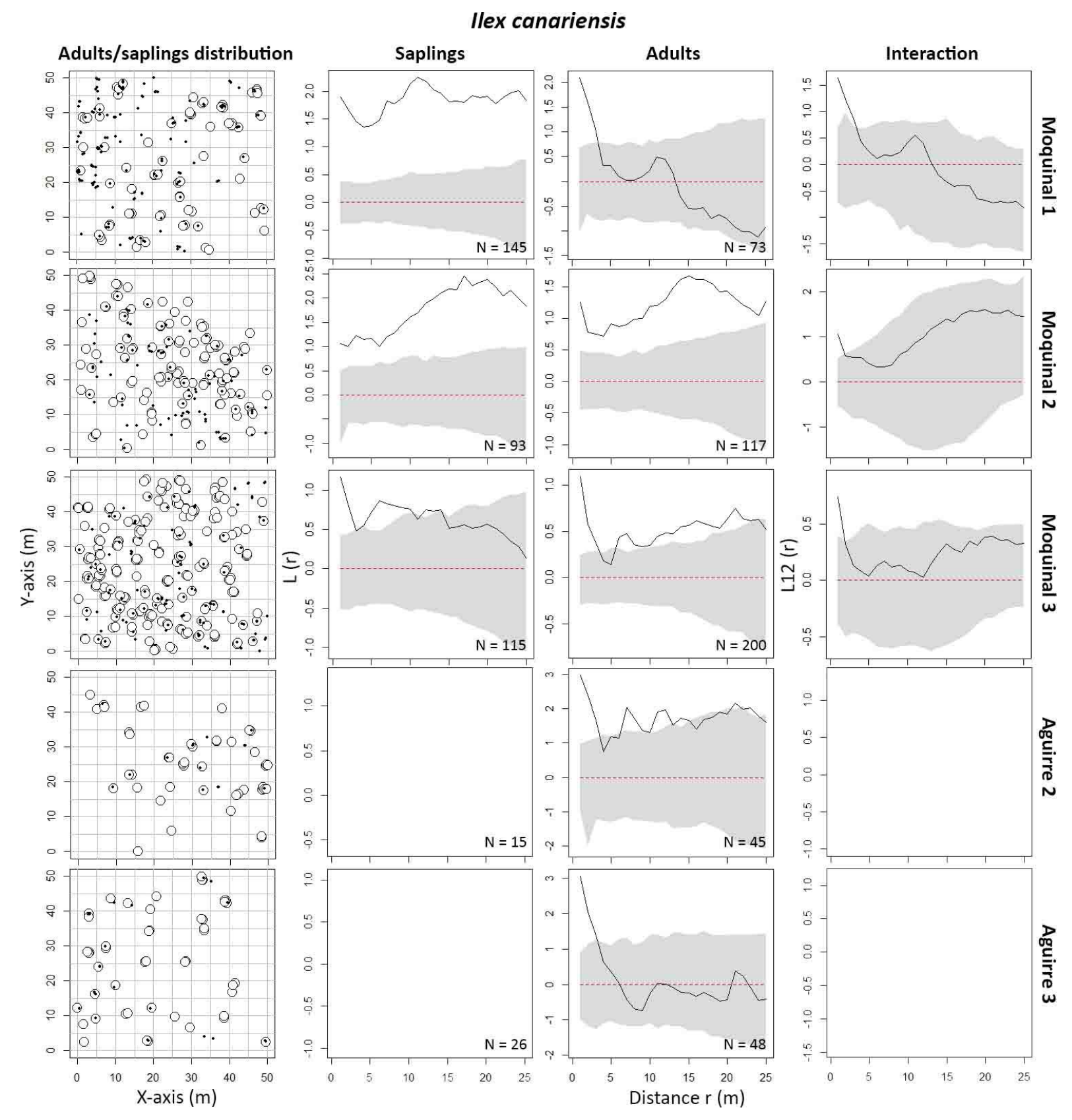

Figure D.4: Spatial distribution and spatial pattern analysis of Ilex canariensis in Moquinal 1-3 and Aguirre 2 and 3. Black circles: saplings, large open circles: adults. Spatial analysis was not carried out for saplings in Aguirre 2 an 3 and for both adults and saplings in Aguirre 1 due to the low number of individuals. Black curves represent observed values of the index and grey area represent the $C I_{99 \%}$ limits of the null hypothesis. $\mathrm{N}$ is the number of points in the plot. 


\section{Laurus novocanariensis}
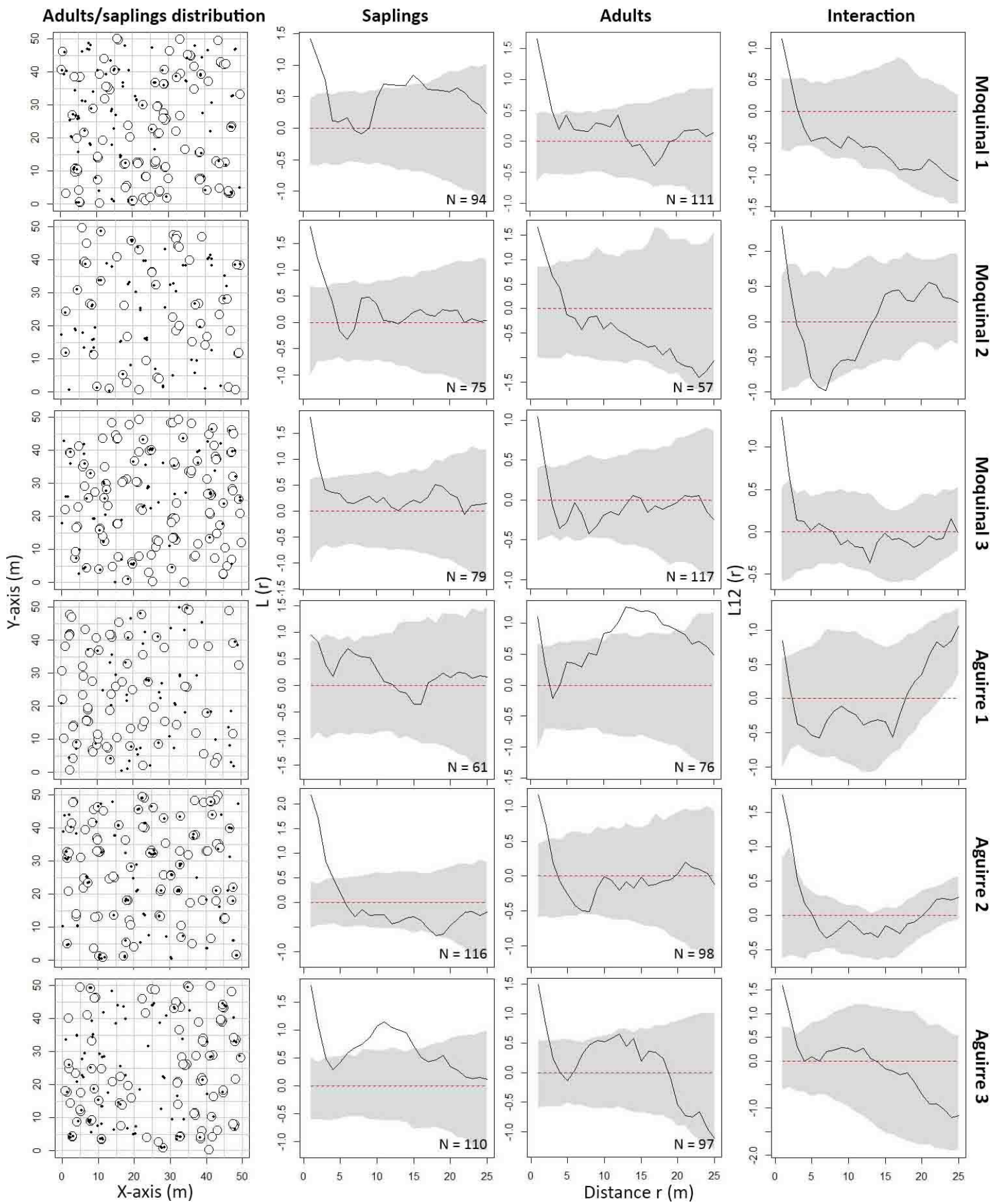

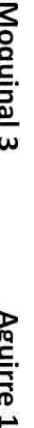
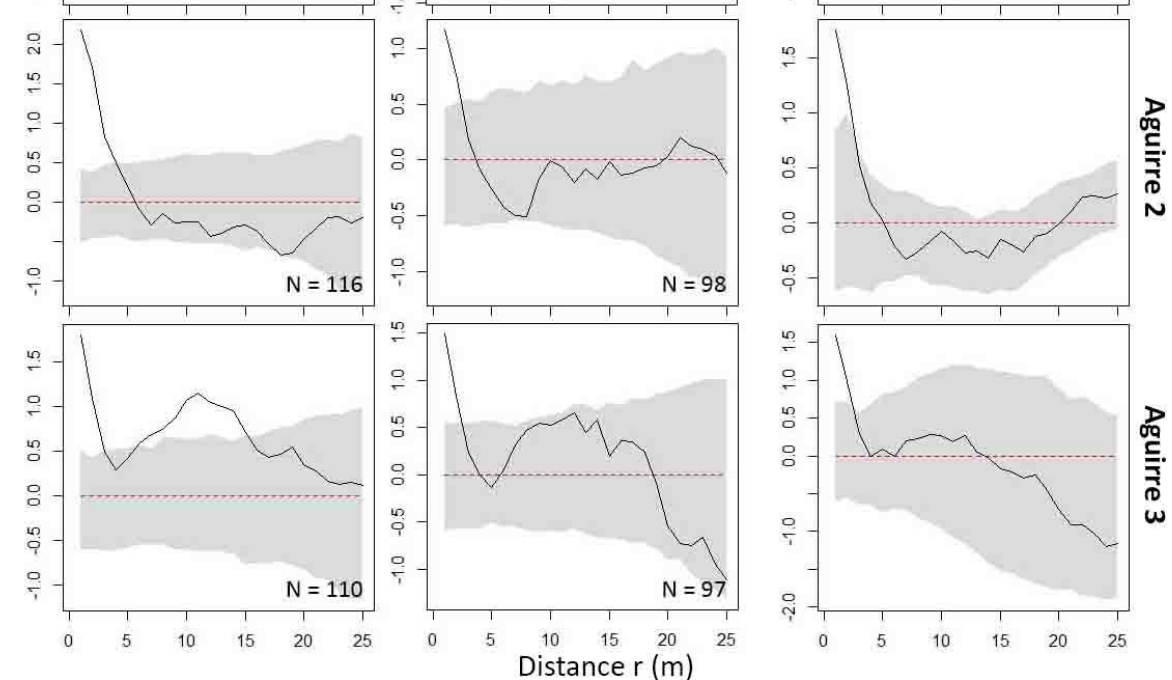

Figure D.5: Spatial distribution and spatial pattern analysis of Laurus novocanariensis in the six sample plots. Black circles: saplings, large open circles: adults. Black curves represent observed values of the index and grey area represent the $C_{99 \%}$ limits of the null hypothesis. $\mathrm{N}$ is the number of points in the plot. 


\section{Morella faya}
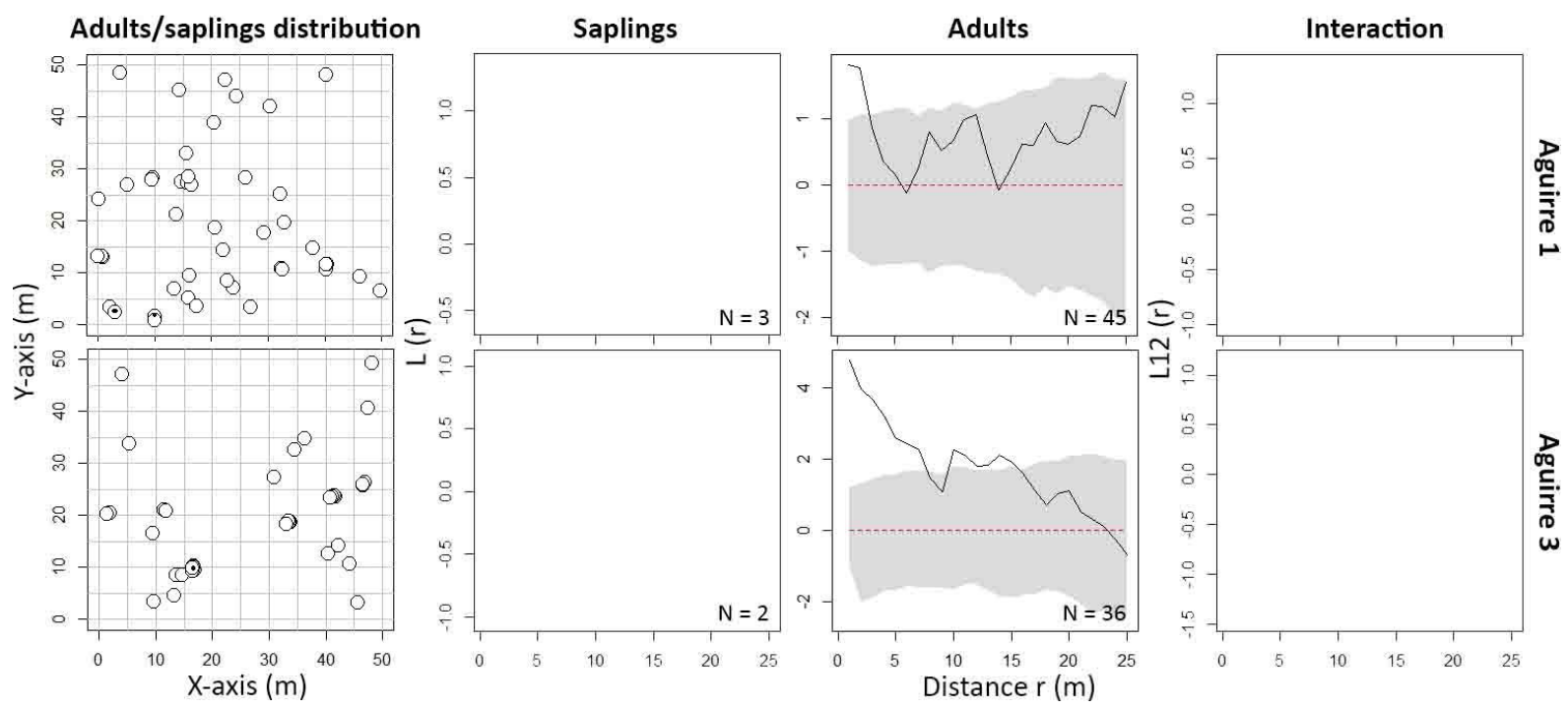

Figure D.6: Spatial distribution and spatial pattern analysis of Morella faya in Aguirre 1 and 3. Black circles: saplings, large open circles: adults. Spatial analysis was not carried out for saplings in these plots and for both adults and saplings in the others due to the low number of individuals. Black curves represent observed values of the index and grey area represent the $C I_{99 \%}$ limits of the null hypothesis. $\mathrm{N}$ is the number of points in the plot.

\section{Prunus lusitanica}
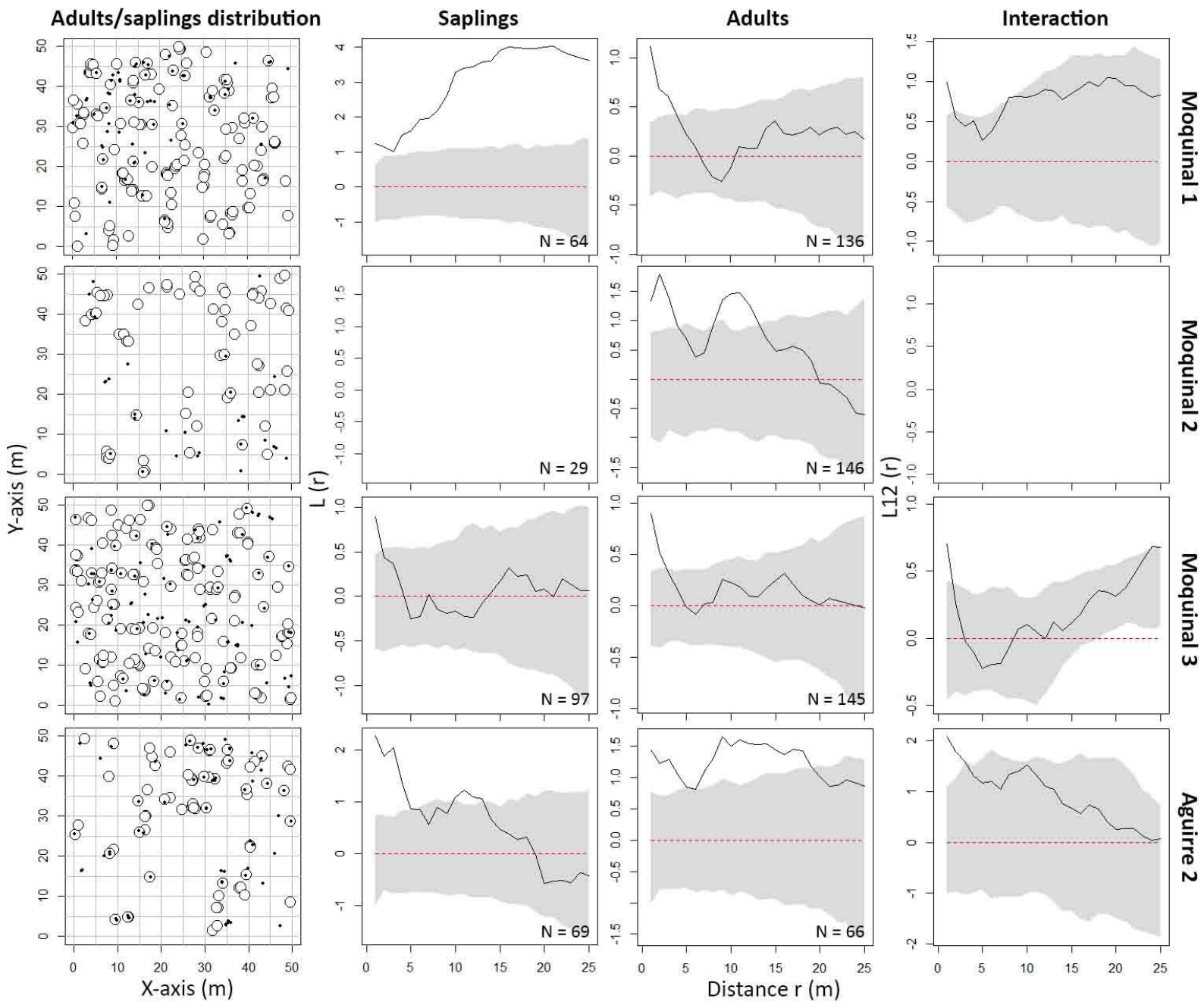
Figure D.7: Spatial distribution and spatial pattern analysis of Prunus lusitanica in Moquinal 1-3 and Aguirre 2. Black circles: saplings, large open circles: adults. Spatial analysis was not carried out for saplings in Moquinal 2 and for both adults and saplings in Aguirre 1 and 3 due to the low number of individuals. Black curves represent observed values of the index and grey area represent the $C I_{99 \%}$ limits of the null hypothesis. $\mathrm{N}$ is the number of points in the plot.
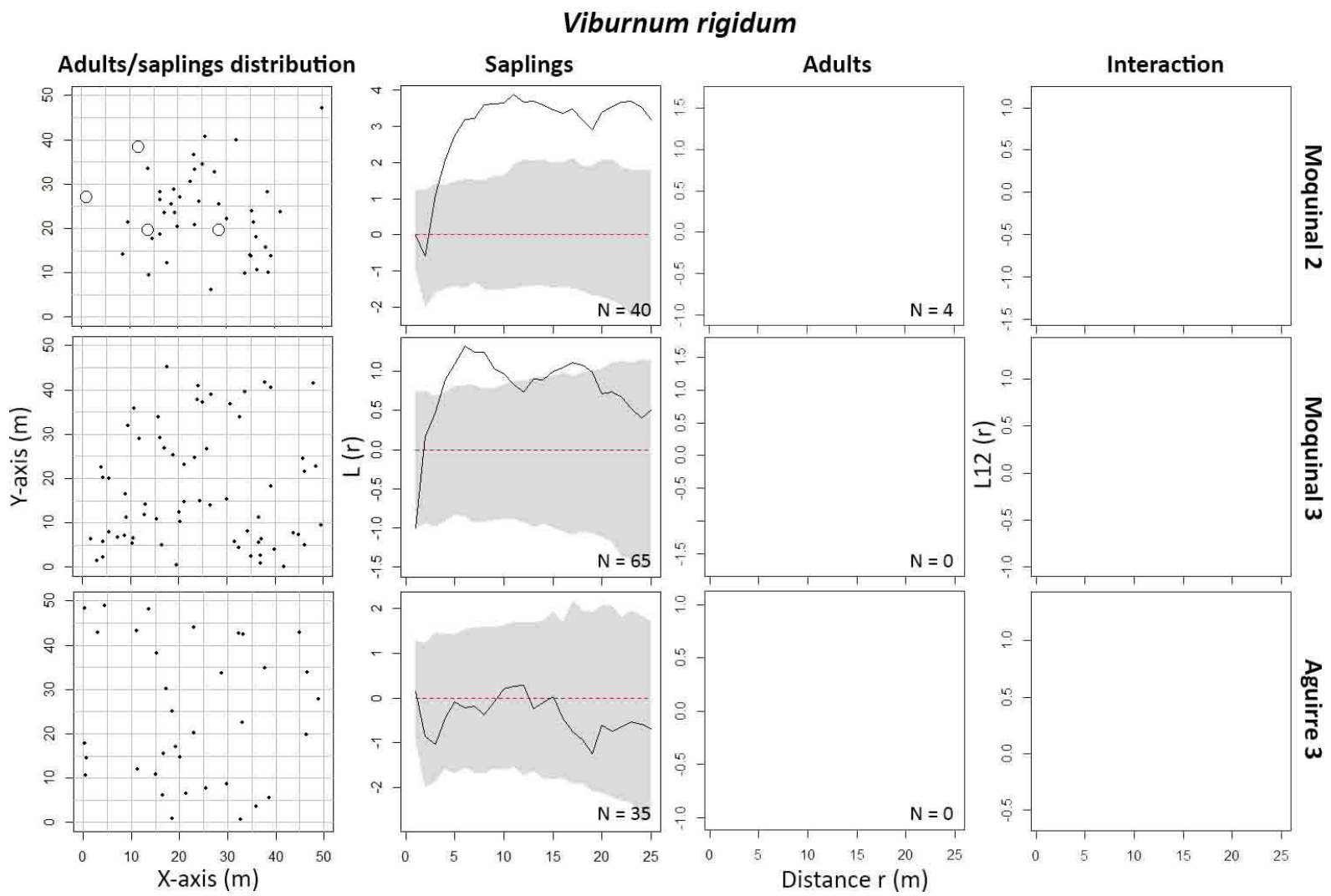

Figure D.8: Spatial distribution and spatial pattern analysis of Viburnum rigidum in Moquinal 2 and 3 and Aguirre 3. Black circles: saplings, large open circles: adults. Spatial analysis was not carried out for adults in these plots and for both adults and saplings in the others due to the low number of individuals. Black curves represent observed values of the index and grey area represent the $C I_{99 \%}$ limits of the null hypothesis. $\mathrm{N}$ is the number of points in the plot. 